\title{
Electrochromic Windows: Advanced Processing Technology
}

\author{
December 13, 2006
}

Sage Electrochromics, Inc.

One Sage way, Faribault MN, 55021

Tel: (507) 3314848

Contract Number: DE-FG36-03G013004

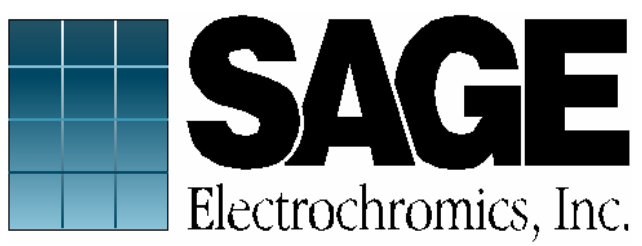




\section{Executive Summary}

This project addresses the development of advanced fabrication capabilities for energy saving electrochromic (EC) windows. SAGE EC windows consist of an inorganic stack of thin films deposited onto a glass substrate. The window tint can be reversibly changed by the application of a low power dc voltage. This property can be used to modulate the amount of light and heat entering buildings (or vehicles) through the glazings. By judicious management of this socalled solar heat gain, it is possible to derive significant energy savings due to reductions in heating lighting, and air conditioning (HVAC).

Several areas of SAGE's production were targeted during this project to allow significant improvements to processing throughput, yield and overall quality of the processing, in an effort to reduce the cost and thereby improve the market penetration.

First, the overall thin film process was optimized to allow a more robust set of operating points to be used, thereby maximizing the yield due to the thin film deposition themselves. Other significant efforts aimed at improving yield were relating to implementing new procedures and processes for the manufacturing process, to improve the quality of the substrate preparation, and the quality of the IGU fabrication.

Furthermore, methods for reworking defective devices were developed, to enable devices which would otherwise be scrapped to be made into useful product. This involved the in-house development of some customized equipment.

Finally, the improvements made during this project were validated to ensure that they did not impact the exceptional durability of the SageGlass ${ }^{\circledR}$ products.

Given conservative estimates for cost and market penetration, energy savings due to EC windows in residences in the US are calculated to be of the order 0.026 quad $\left(0.026 \times 10^{15} \mathrm{BTU} / \mathrm{yr}\right)$ by the year 2017 . 


\section{Table of Contents}

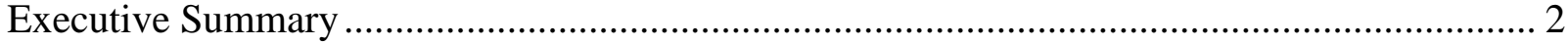

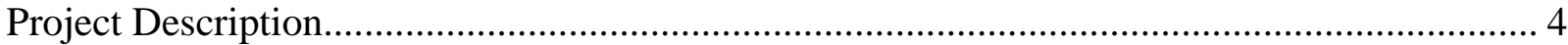

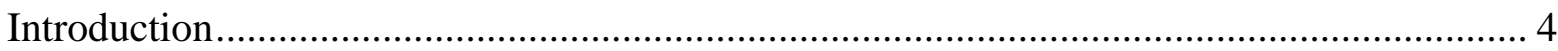

Original Project Goals and Objectives......................................................................... 4

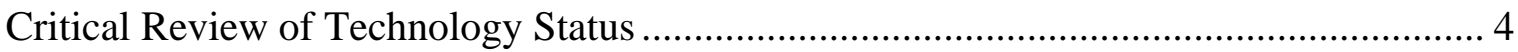

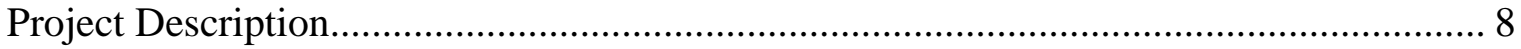

Anticipated Benefits of the Project ................................................................................ 11

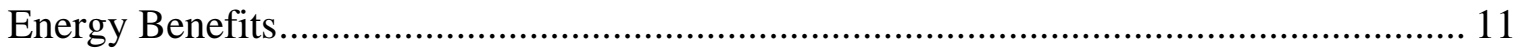

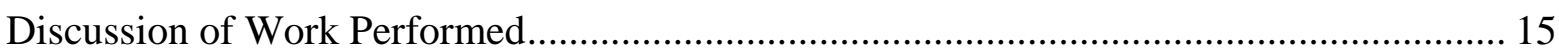

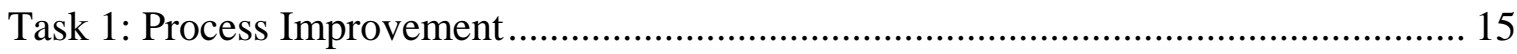

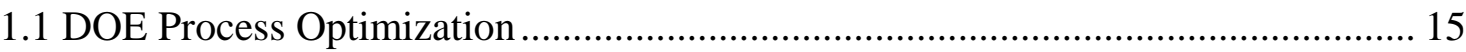

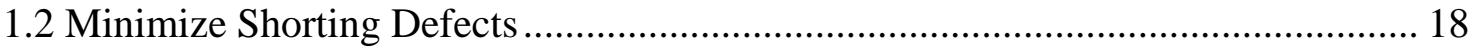

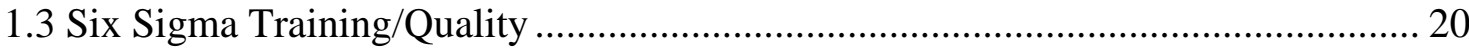

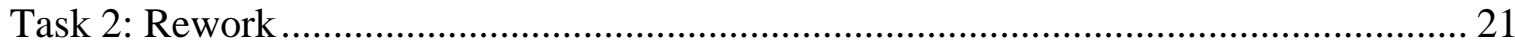

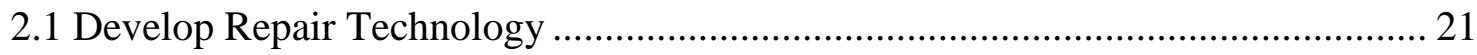

2.2 Develop Semi-Automated Equipment ............................................................. 23

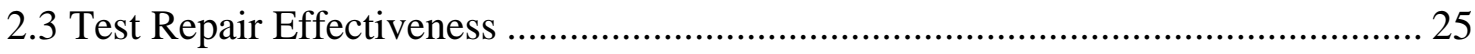

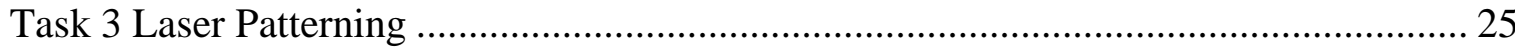

3.1 ID Laser system and Develop Process .............................................................. 25

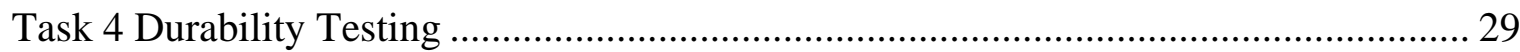

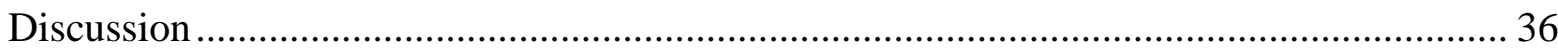

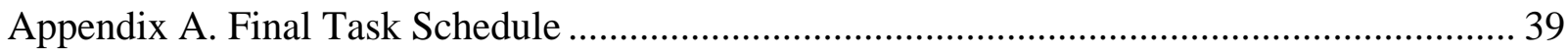

Appendix B. Final Spending Schedule .......................................................................... 40

Appendix C. Final Cost Share Contributions ...................................................................... 41

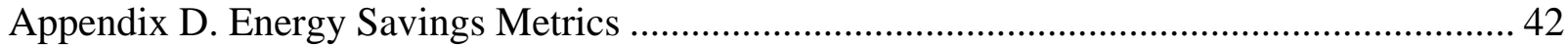




\section{Project Description}

\section{Introduction}

This project addresses the problems of bringing the SageGlass ${ }^{\circledR}$ electrochromic (EC) glazing process from the development stage which it was in at the beginning of the project, to a position where profitable commercial production can be undertaken. Several of the key elements for yield improvements and effective production techniques are covered by the project, and these are discussed in detail later. The report will begin by summarizing the need for EC windows, and then discuss the specific improvements which were targeted in this project. Next, details of the work carried out and the results achieved will be discussed, and some conclusions drawn.

\section{Original Project Goals and Objectives}

\section{Critical Review of Technology Status}

There is a need to improve the energy efficiency of building envelopes because they are the primary factor governing the heating, cooling, lighting and ventilation requirements of buildings - influencing 53\% of building energy use ${ }^{1}$. In particular, windows contribute significantly to the overall energy performance of building envelopes. Thus there is a need to develop advanced energy efficient window glazing systems.

The electrochromic (EC) window represents the next generation of glazing technology which will both reduce the energy consumed in, and improve the overall comfort of, buildings. "Switchable" EC windows provide, on demand, dynamic control of visible light, solar heat gain and glare without blocking the view. As exterior light levels change, the window's performance can be electronically adjusted to suit conditions. Figure 1 shows the SageGlass ${ }^{\circledR}$ IGU. Existing energy efficient windows such as Low

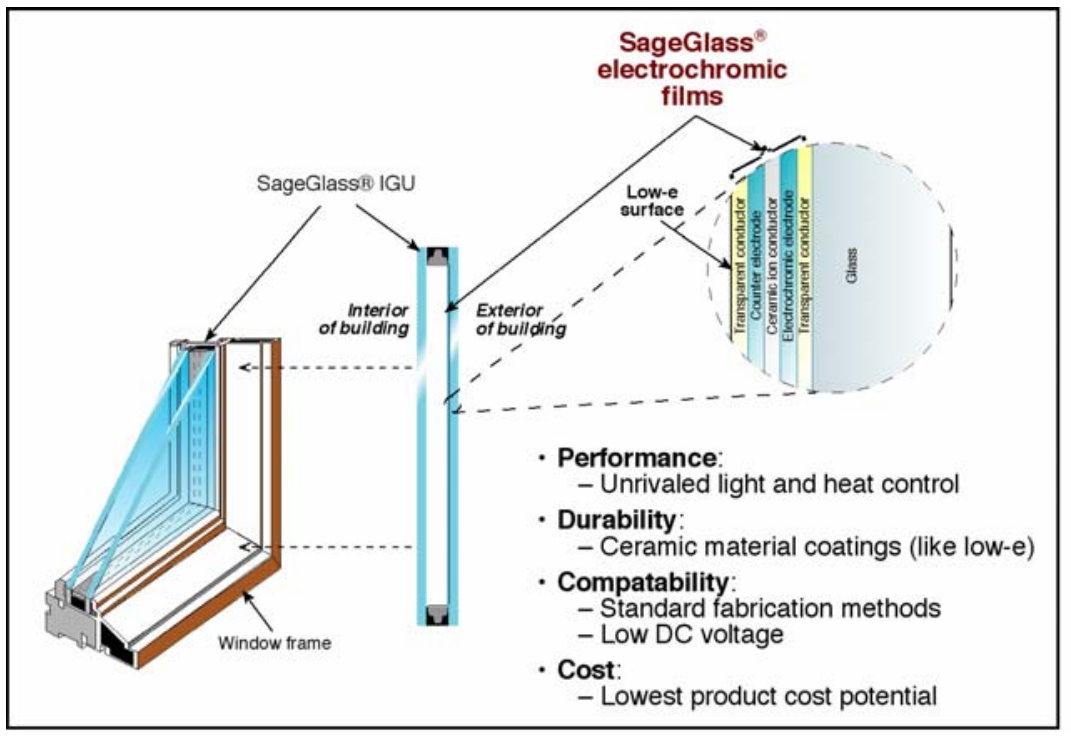

Figure 1 -The films that compose the EC device are shown at right; the SageGlass ${ }^{\circledR}$ IGU is shown in a window frame, at left. Emissivity (Low-E) or reflective glazings sold today are static in nature in that their light and

\footnotetext{
${ }^{1}$ Data contained in the NETLIII solicitation, 2001.
} 
heat transfer performance can not be changed to provide optimum energy savings. Moreover, Low-E glazings have reached the limit of physics in terms of their ability to be optimized for further energy savings. In addition to offering the potential to save cooling and lighting costs, EC glazings also provide the added benefit of improving knowledge worker productivity through better thermal and visual comfort.

SAGE had been developing a durable EC window technology for over a decade, and during this time has overcome numerous key technical hurdles. At the time of the project proposal, SAGE has taken its technology from laboratory scale process and materials development (on $1 \mathrm{ft}^{2}$ size samples) to a $15,000 \mathrm{ft}^{2}$, limited capacity, pilot line operation which we designed and built in 1999. With this pilot line SAGE had (i) successfully proven the feasibility of process scale-up by producing the first large-area prototype EC (SageGlass ${ }^{\circledR}$ ) glazings $\left(5 \mathrm{ft}^{2}\right)$ using durable all-ceramic technology, (ii) delivered full size samples to partners and customers for market and product development, (iii) installed an initial field test site containing full size SageGlass ${ }^{\circledR}$ product and (iv) delivered samples to NREL which have successfully passed durability testing. To date, SAGE has been granted over 50 US and foreign patents on the materials, processing and product technology. SAGE owns all rights to SageGlass ${ }^{\circledR}$ technology on glass and polymer substrates. With this foundation of technical achievement, SAGE was obviously capable and its EC technology was ready for the manufacturing equipment and process developments, which are the subjects of this proposal and are discussed in this report.

There are four key requirements for successful commercialization of an EC exterior glazing product: durability, exceptional heat and light control performance, capability for cost effective manufacturing and compatibility with existing window product configurations. At the time of the proposal, SAGE was - and, incidentally, continues to be - the only EC developer that has proven its technology meets all of these requirements, which, importantly, has been recognized not only by the DOE, but by key window OEMs and leading glazing manufacturers.

The electrochromic (EC) window represents the next generation of advanced glazing technology that will both reduce the energy consumed in buildings, as well as improve both the overall comfort of the occupants and the thermal performance of the building envelope. ${ }^{2}$ "Switchable" EC windows provide, on demand, dynamic control of visible light, solar heat gain, and glare without ever blocking the view. ${ }^{3}$ As exterior light levels change, the performance of the window can be electronically adjusted to suit conditions. A schematic diagram illustrating how SageGlass ${ }^{\circledR}$ electrochromic windows work is shown in Figure 2. In the 'clear state', depicted in the uppermost diagram, both solar heat and visible light are allowed to pass through the window. In this condition, the window is practically indistinguishable from a 'normal' window glazing, typically permitting upwards of $60 \%$ of the direct visible light to be transmitted. This 'clear' condition allows the building occupant to maximize the natural daylight and heat flowing through the window, thereby reducing the requirements for lighting and heating.

\footnotetext{
${ }^{2}$ C.G.Granqvist, Crit. Rev. Solid State Mater. Sci. 16, 291-308 (1990); C.M.Lampert, Solar Energy Materials, 11, $1-27$ (1984)

${ }^{3}$ For more details on this see: http://www.sage-ec.com
} 


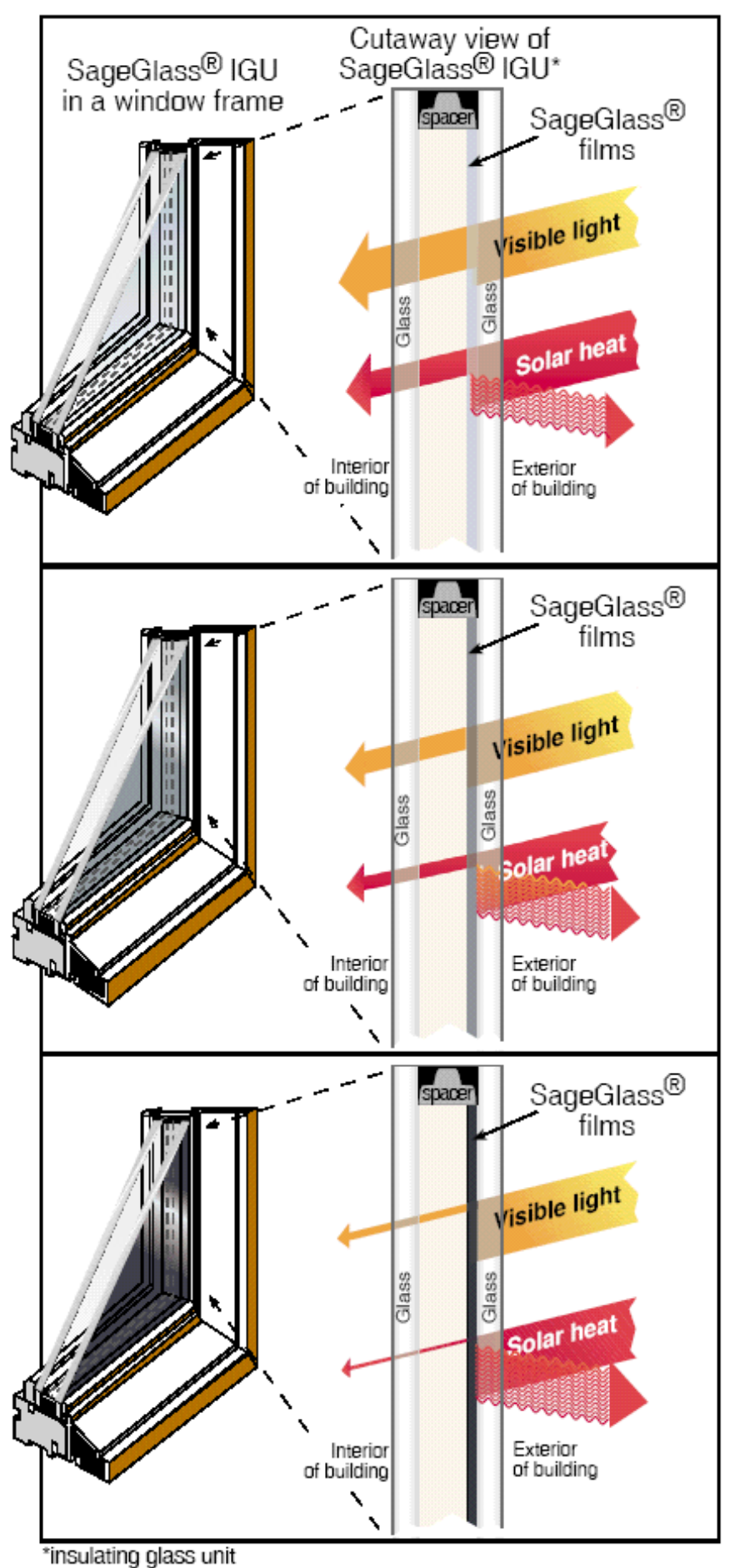

Figure 2 - Schematic of the principle of operation of a SageGlass ${ }^{\circledR}$ EC window.
However, should the need arise, it is possible for the building occupant to reduce the level of transmitted light from the clear state, in order to reduce the visible light and solar heat gain into the building. A typical dark state visible transmission for a SageGlass ${ }^{\circledR}$ window is around $3 \%$. This is accomplished by electrochemically inducing absorption in the thin film stack, the absorbed energy being thermalized and then re-radiated to the outside as a result of a low-e surface, which is an intrinsic part of the SageGlass ${ }^{\circledR}$ EC device.

The ability to block solar energy is particularly useful in warmer climates where cooling requirements dominate, as it will reduce the overall load on the cooling systems. It should be noted that control over solar heat gain will also result in the use of smaller and therefore more economical air conditioning equipment. In addition, the reduction in visible light gain can be used to reduce glare in the office environment - useful for 'knowledge workers', and especially those using computers. It should be noted that the transmission can be held at any point between fully dark and fully clear, and that this is a fairly simple matter of electronic control, and that the coloration and bleaching are totally reversible.

Control of EC windows is highly flexible. They can be arranged to be part of a totally automatic integrated building energy management system, or can be individually controlled by users. EC windows operate using very low levels of electrical power. Typical voltages are between 1 and $3 \mathrm{~V}$, with currents of 
less than $1 \mathrm{Am}^{-2}$, and these requirements can be met from various sources, including photovoltaic cells.

As is obvious from the preceding discussion, SageGlass ${ }^{\circledR} \mathrm{EC}$ glazing offers huge potential in cooling and lighting cost reductions, with the added benefit of improving thermal and visual comfort. ${ }^{4}$ This will lead to a reduction in the energy consumption, and thereby reduce the US dependence upon foreign oil imports.

The outermost layers are transparent conductors (TC), which are used to apply a voltage to the

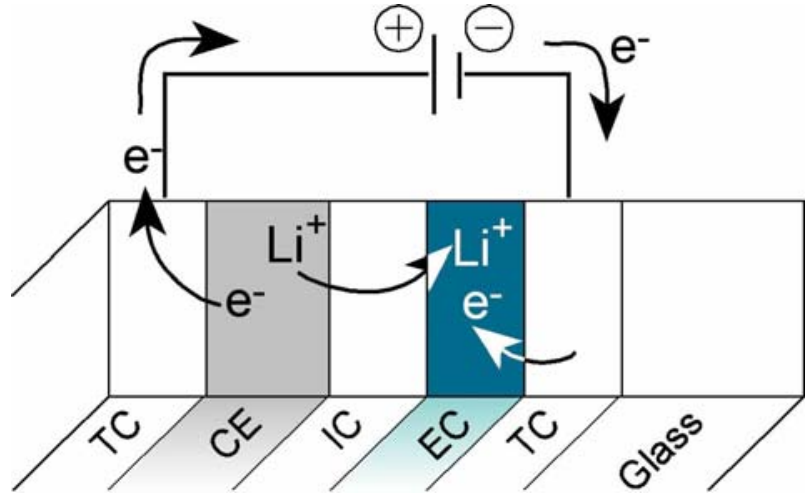

Figure 3 - The SageGlass ${ }^{\circledR}$ electrochromic device active layers that are sandwiched between. These active layers consist of an EC layer, an ion conductor (IC) layer, and a counter electrode layer (CE). Charge, in the form of electrons and ions, is shuttled between the $\mathrm{CE}$ and the EC layers, producing the bleached and colored states respectively: The electrons are passed around the outer circuit, while the ions are transported through the IC. Insertion of charge into the EC layer will cause that layer to color to a depth depending upon the amount of charge transferred. The effect is completely reversible, and is accomplished simply by reversing the polarity of the voltage. The polarity for coloration is shown in Figure 3.

If a step change in the energy efficiency and performance of buildings is to be achieved, there is a clear need to bring EC technology to market. This proposal addressed a number of key process technology improvements that had to be completed in order to accelerate the introduction and adoption of EC windows in buildings and thus maximize total energy savings in the US and worldwide. The focus of these developments was on improving manufacturability and process yields, both of which will result in moving more rapidly toward full commercialization and lower manufacturing costs.

The SageGlass ${ }^{\circledR}$ EC device is a series of thin films deposited onto a glass substrate one on top of the other to form a stack. ${ }^{5}$ This is shown in Figure 3, and is known as an 'all solid-state ECsystem', to distinguish it from an EC window with a polymeric electrolyte - 'a polymeric ECsystem'. The all solid state system is much more difficult to produce, because any imperfections in the coating - pinholes, etc. - will lead to short circuits between the two transparent conductors, which in turn will lead to highly noticeable defects. The polymeric approach does not suffer from this problem, as a thick layer of insulating polymeric material separates the transparent conductors.

\footnotetext{
${ }^{4}$ E.S.Lee, D.L.DiBartolomeo, F.M.Rubinstein, and S.E.Selkowitz, 'High Performance Commercial Building Systems - Low-cost Networking for Dynamic Window Systems’, Submitted to Energy and Buildings, August 2003.

${ }^{5}$ C.G.Granqvist, 'Handbook of Inorganic Electrochromic Materials’, Elsevier (1995), Chapter 1 p1
} 
However, the polymeric device has three significant disadvantages when compared to the allsolid state system: (1) The polymeric materials are generally unstable to solar radiation, and will therefore give very poor durability in applications where solar exposure is a possibility i.e. most window applications; (2) the polymeric IGU system requires at least ${ }^{6}$ three sheets of glass, increasing the cost, and significantly increasing the weight. The fact that there are at least three sheets of glass means that original equipment manufacturer's (OEM) framing systems need to be redesigned, giving further increases in cost; (3) the polymeric system does not provide the EC window with a low-e surface, thereby compromising the energy efficiency of the system.

The SageGlass ${ }^{\circledR}$ all solid-state EC device does not suffer from any of these issues. It is fabricated from inorganic materials, which lead to excellent durability when exposed to solar radiation, high temperatures, etc. It can be deposited onto tempered glass, giving it the required structural integrity for use in building applications, and can be fabricated into an IGU that is an almost direct replacement for a standard IGU, requiring minimal re-engineering of the framing system. Finally, the uppermost transparent conductor acts as a low-e surface, giving it excellent thermal performance.

\section{Project Description}

This project was focused on processing-technology improvements needed to manufacture EC glazings at high yield and low cost. At the start of the project, SAGE had developed a unique EC thin-film device structure, as well as the metal oxide materials required to produce durable switchable glazings with good dynamic range. Initial laboratory studies followed by pilot line trials had demonstrated the capability for fabrication of window glazings up to $5 \mathrm{ft}^{2}$. However, there were a number of process issues that had to be addressed to consistently produce EC devices at the projected $75 \%$ yield. We proposed identifying and optimizing important process variables using a statistical approach for determining cause-and-effect relationships. In particular, we focused on minimizing short-type defects, and then on developing an efficient rework procedure to excise the remaining random shorts occurring at low defect densities. Another yield-impacting process was the patterning of the conductive films to achieve isolation between oppositely biased electrodes. A laser tool was developed to replace microsandblasting with its associated debris and consequent defects. Finally, accelerated testing was carried out to qualify EC devices with new and improved processing steps and to ensure maintenance of the excellent durability performance of this solid state product.

The project was broken into four major task areas, and the overall aims of each are described below.

Task 1 - Process Improvement. The challenge was to identify those key processing variables, among the multiple fabrication steps, that have the most impact on yields and throughput. This is difficult if not impossible to do without a carefully planned progression of statistically designed experiments to locate the optimum, most robust operating points. The

\footnotetext{
${ }^{6}$ In polymeric systems, the 'laminating' polymer electrolyte is too weak to be used as a safety laminate. Many times, therefore, it is necessary to laminate a further sheet of glass to the device in order for it to have the structural integrity to be used in construction applications.
} 
approach taken was to implement and utilize Design of Experiments (DOE) techniques. The SAGE technical team had attended an intensive course on DOE and was to undergo 6 sigma training provided by our Honeywell partner. This training gave SAGE technical personnel the ability to design and analyze optimization experiments and implement process quality enhancements that were to result in higher yields and more rapid commercialization.

The task to minimize shorting defects was an important part of this project. These defects can originate at several steps in glazing fabrication (e.g. interconnect application, tempering, washing, or coating). The variance in defect density is large and DOE techniques were to be used to identify their most likely sources. This effort was assisted through the use of electron beam analytical tools (SEM, energy dispersive x-ray analysis, and Auger amongst others) to identify the constituent atomic species in these 1-10 micron particles. We had observed that not all particles present in the stack result in shorts. Therefore, it was important to try to correlate observed electrical shorts with certain particle characteristics (size, composition, and location in film stack). Once root causes were identified, we anticipated that countermeasures could be employed to reduce defect densities by more than an order of magnitude. Total elimination of the few remaining shorting defects would then be achieved in the following rework task.

\section{Detailed tasks}

1.1 Optimize thin-film coating and thermal processing operations: SAGE was to implement statistical design of experiment (DOE) procedures to identify and control key thin film deposition and heating process variables for improved device yields. This approach was to enable rapid convergence to a robust process space in which sputtering parameters, film thicknesses, firing times and temperatures are controlled for optimum performance.

1.2 Determine origins and minimize shorting defects: Electrical shorts between thin-film electrodes are a cause of EC device rejects. These defects can be smaller than 10 microns and can originate from several process steps. While the short may be small, the affected device area is much larger and visible. In this task, state-of-the-art chemical and physical characterization tools available at the Univ. of Minnesota's Center for Interfacial Science were to be utilized to determine the composition of the shorts and at what step in the process they were introduced. Suspect processes will be redesigned to minimize shorting events.

Task 2 - Glazing Rework. Although we planned to significantly reduce defect densities, it is clear that there will always be a small residual level, and so some percentage of panes will need to be repaired to achieve high product yields. Generally, in the glass industry, it is possible to cut around defects, to salvage otherwise unusable product. However, this is not possible for us, because all the glass which is process is cut to size and tempered prior to depositing the EC coatings. This means that a percentage of the glazings that might otherwise be salvageable are scrapped because they have been heat strengthened or tempered and therefore can not be cut down into smaller sized product. Preliminary work has shown that precision high current pulses can vaporize defects with undetectable cosmetic damage. The challenge was to develop a repair tool to rapidly move to the defect area, precisely locate the tiny particle in the center of a visible short, and vaporize it.

\section{Detailed tasks}

2.1 Develop repair technology: Very successful preliminary work had shown that shorts 
and other cosmetic defects could be removed by directing a high current pulse through the defect. To achieve non-destructive repair the waveform and frequency of the current pulses had to be optimized and appropriate hardware and software developed. The goal here was to vaporize the defect and leave a $<50$ micron hole in the thin films, which is invisible in the final device.

2.2 Design/construct semi-automated equipment: The object was to incorporate the above repair technology into a semi-automated process tool for rapidly removing multiple defects from large area glazings (currently $0.5 \mathrm{~m} \times 1.0 \mathrm{~m}$ ). First the precise location of each short had to be determined. We anticipated roughly locating the defect with a CCD camera and then using a stepped electrical probe to pinpoint the short at a potential minimum in the EC device. Once located, the appropriate current pulse(s) can be delivered prior to moving to the next one.

2.3 Test repaired devices: Evaluate optical and electrical performance of repaired devices. While hard shorts are eliminated, we didn't want to create additional electrical problems through the pulsed current vaporization of film materials. Multiple devices will be carefully examined.

Task 3 - Laser Patterning. Glass substrates for EC devices are coated with a transparent conductive oxide (TCO) film. Electrical isolation of the two electrodes is achieved by creating discontinuities in the TCO. At the time of the proposal, a sandblasting technique was being employed, but this by its very nature produces defect causing debris (the sand), which then had to be carefully removed without scratching the TCO. Hence, a more precise, cleaner, faster approach was needed. The photovoltaic industry has used YAG lasers to isolate conductive tin oxide films on glass. SAGE proposed to build on that capability and develop a laser process to achieve good electrical isolation without cracking the underlying glass or leaving debris that would affect the performance of subsequently deposited layers. The successful completion of the task would result in design specifications for an automated laser patterning system.

\section{Detailed tasks:}

3.1 Identify laser system and process parameters: Partner with Control Micro Systems, Inc. to determine the appropriate wavelength, power, focused spot configuration, and substrate orientation to effectively remove the FTO material with little damage to the underlying glass and minimal debris. Demonstrate the capability to scribe an isolation line up to 1 meter in length. Specify parameters for Pilot Line laser isolation system.

3.2 Build and test laser isolated EC windows: Fabricate complete EC windows with laser-isolated substrates. Measure performance. Determine whether or not high leakage and/or shorting occur at the laser kerf. Determine whether laser scribing and isolation can be used to eliminate one of the masking steps used to pattern films when fabricating an EC device.

Task 4 - Qualification/Durability Testing. Durability testing must be carried out to ensure the robustness of the EC devices that are fabricated using the above improved processes. The National Renewable Energy Laboratory has the equipment and personnel required to efficiently carry out this task. They have several years experience in evaluating the performance of EC devices, and serve as an objective third party in reporting EC glazing performance.

Detailed tasks: 
4.1 Carry out solar simulator tests: Windows for durability evaluations were to be prepared at SAGE and sent to the National Renewable Energy Laboratory for testing in their Atlas XR-260 environmental chamber under 1-sun simulated irradiation at elevated temperature while being rapidly cycled between clear and dark states. The test protocol follows ASTM standard E2141-01 for absorptive electrochromic coatings in sealed insulating glass units. NREL is specifically funded for this work under DOE contract DE-AC3699GO110337.

\section{Anticipated Benefits of the Project}

For the purpose of this simulation, the (installed) unit for measurement of this EC technology is a three-story typical office building with a window to wall ratio (WWR) of 0.60 (most closely approximates a highly glazed building) glazed with EC glass. The energy usage in the EC glazed building will be compared with energy usage for the same building glazed with either a reflective glass or a high performance spectrally selective low-e coated glass. We have selected the comparative glazings that represented the best performing products on the market today.

The data presented in this section are for commercial buildings, whereas the data in the appendix are calculated for residential buildings, however we expect the general lessons learned to be transferable between commercial and residential, albeit with some slight adjustments to the actual energy benefits as a result of the different building layout and WWR.

\section{Energy Benefits}

To quantify the energy saving benefits projected for EC technology over conventional static glazings, we have used a computer simulation analysis of these prototypical buildings previously performed by the Building and Daylighting Group at LBNL ${ }^{7}$. The results provide a measure of the annual energy consumption of each of the buildings with the different glazing types. The analysis involved an hour-by-hour DOE-2.1E energy simulation to calculate the annual cooling, lighting, and heating energy consumption as well as peak demand. The conventional static glazings were modeled with movable interior shades that were used with a probability factor of 0.7. The solar and optical properties of the glazings are shown in Table 1.

\footnotetext{
${ }^{7}$ The analysis was carried out by Bob Sullivan of LBNL in late 1997 and early 1998.
} 
Table 1 - The solar and optical properties of the SageGlass ${ }^{\circledR}$ and comparative glazings

\begin{tabular}{|l|l|l|l|}
\hline Glazing & $\begin{array}{l}\text { Solar Heat Gain } \\
\text { Coefficient (SHGC) }\end{array}$ & $\begin{array}{l}\text { Visible light* transmission } \\
\text { (Tvis) }\end{array}$ & $\begin{array}{l}\text { U-Factor* W/m2K } \\
\text { (BTU/hr-ft2F) }\end{array}$ \\
\hline Spectrally Selective & 0.37 & $70 \%$ & $1.66(0.29)$ \\
\hline Reflective & 0.13 & $8 \%$ & $2.20(0.39)$ \\
\hline SageGlass $®$ EC & 0.43 (clear) -0.10 (dark) & $59 \%($ clear $)-4 \%($ dark) & $1.87(0.33)$ \\
\hline
\end{tabular}

*The SHGC and Tvis are values at ASHRAE summer conditions. The U-Factor values are at ASHRAE winter conditions.

\section{Assumptions and additional input data}

The other major assumptions made and input data for the calculation are as follows: The building is located in Phoenix, Ariz., and consists of ground and rooftop floors and one intermediate floor. Each floor has a perimeter floor area of $556 \mathrm{~m}^{2}$ and a core zone of area $929 \mathrm{~m}^{2}$. For a WWR of 0.60 , there is 8,640 sq.ft of glazing area. A peak occupancy of 390 was used and lighting loads and equipment loads were $12.9 \mathrm{~W} / \mathrm{m}^{2}$ and $8.1 \mathrm{~W} / \mathrm{m}^{2}$ respectively. The the energy savings predicted from use of EC compared to the existing technologies derived from the DOE2.1 analysis are summarized in Table 2. The model predicts that installation of EC glazings saves $12 \%$ over reflective and $16 \%$ over spectrally selective glazings.

The energy saved through the use of EC glazings is likely to be substantially higher than projected by this calculation for a number of reasons. First, the glazings in the installed base and new construction do not comprise only the highest energy performing products as we have compared here. In new construction commercial buildings, low-e and reflective glazings only account for $16 \%$ and $21 \%$ of the market share respectively. Secondly, LBNL's analysis did not include the use of occupancy sensors (which could substantially reduce cooling costs in the summer and heating costs in the winter simply by switching SageGlass ${ }^{\circledR}$ windows to the completely darkened or clear states at the appropriate times). Thirdly, for this evaluation we used the current performance of SageGlass ${ }^{\circledR}$ windows, but we anticipate significant improvement as the product matures. Finally, and more difficult to quantify, EC glass should allow architects and engineers to design buildings which better capture and utilize the sun's natural lighting while minimizing the cooling energy load. Although within the scope of this proposal we cannot justify the extension of these calculations to national energy savings, we have, as part of a NETLIII proposal recently calculated the total annual US energy savings at ultimate market penetration and estimated a saving of 0.71 quads of energy and \$11.5 billion. 
Table 2 - Summary of the energy analysis using the DOE2.1 model comparing an EC glazed building with identical buildings glazed with Low-E and reflective glazings $\left({ }^{*}\right.$ Mbtu $=$ Million Btu).

\begin{tabular}{|c|c|c|c|c|c|c|c|c|c|}
\hline \multicolumn{2}{|c|}{$\begin{array}{l}\text { Annual Energy } \\
\text { Usage in } \\
\text { Perimeter zone }\end{array}$} & \multirow{3}{*}{$\begin{array}{l}\text { Cooling } \\
\text { Mbtu* }^{\star}\end{array}$} & \multirow{3}{*}{$\begin{array}{l}\text { Light } \\
\text { Mbtu }\end{array}$} & \multirow{3}{*}{$\begin{array}{l}\text { Total } \\
C \& \& \\
\text { Mbtu }\end{array}$} & \multicolumn{2}{|l|}{ Heating } & \multirow{3}{*}{$\begin{array}{l}\text { Total H, C } \\
\& \mathrm{~L} \\
\\
\text { Mbtu }\end{array}$} & \multirow{3}{*}{$\begin{array}{l}\text { Peak } \\
\text { C\&L } \\
\\
\text { (W) }\end{array}$} & \multirow{3}{*}{$\begin{array}{l}\text { Peak } \\
\text { Heating } \\
\text { KBtu/hr }\end{array}$} \\
\hline & & & & & \multirow{2}{*}{$\begin{array}{l}\text { Energy } \\
\text { MBtu }\end{array}$} & \multirow{2}{*}{$\begin{array}{l}\text { Fan } \\
\text { (MBtu) }\end{array}$} & & & \\
\hline & & & & & & & & & \\
\hline \multicolumn{2}{|l|}{$\mathrm{EC}$} & 397 & 141.7 & 538.7 & 75.9 & 7.3 & 621.9 & 110,225 & 316.5 \\
\hline \multicolumn{2}{|l|}{$\begin{array}{l}\text { Spectrally } \\
\text { Selective }\end{array}$} & 491 & 140.8 & 631.8 & 99.1 & 10.4 & 741.4 & 127,812 & 302.2 \\
\hline \multicolumn{2}{|l|}{ Reflective } & 385 & 216.5 & 601.5 & 96.3 & 8.0 & 705.8 & 112,475 & 385.5 \\
\hline \multicolumn{10}{|c|}{ Energy savings } \\
\hline \multirow{2}{*}{$\begin{array}{l}\text { EC vs } \\
\text { Spectrally } \\
\text { Selective }\end{array}$} & Btu & 94 & -0.9 & 93.1 & 23.2 & 3.1 & 119.5 & 17,587 & -14.3 \\
\hline & $\%$ & $19 \%$ & $-0.6 \%$ & $15 \%$ & $23 \%$ & $30 \%$ & $16 \%$ & $14 \%$ & $-4.7 \%$ \\
\hline \multirow{2}{*}{$\begin{array}{l}\text { EC vs } \\
\text { Reflective }\end{array}$} & Btu & -12 & 74.8 & 62.8 & 20.4 & 0.7 & 83.9 & 2,250 & 69 \\
\hline & $\%$ & $-3 \%$ & $35 \%$ & $10 \%$ & $21 \%$ & $10 \%$ & $12 \%$ & $2 \%$ & $18 \%$ \\
\hline
\end{tabular}

\section{Economic benefits}

EC glazings will be sold into the construction window markets (both residential and commercial) and also the transportation markets - for heat and light control. This latter application, not included in the above analysis, will also result in a reduction in the use of fossil fuels by increasing the fuel economy in automobiles by downsizing AC units. The commercialization of EC glazings will cause significant economic benefits through (i) the reduction in energy demand, (ii) the building of a new billion dollar technology industry and (iii) the productivity benefits provided to knowledge workers in buildings glazed with EC. 


\begin{tabular}{|l|l|l|}
\hline Year & $\begin{array}{l}\text { Price } \\
\left(/ \mathrm{m}^{2}\right)\end{array}$ & $\begin{array}{l}\text { \% penetration in } \\
\text { construction } \\
\text { mkts }\end{array}$ \\
\hline 2011 & $\$ 250$ & $8 \%$ \\
\hline 2017 (maturity) & $\$ 150$ & $14 \%$ \\
\hline
\end{tabular}

Table 3 - Summary of anticipated sales volumes of EC windows
Table 3 contains a summary of the anticipated sales volumes and penetrations of EC in 2011 and 2017. The current volume is zero. Our estimates of penetration are based on a comparison with the historical pricing of low-e window systems (introduced first in 1980 and reaching maturity now), feedback from market surveys, focus groups and OEM customers. It

is anticipated that the market penetration for commercial buildings will be somewhat higher than those for the residential market, so we can see that it is clear that the energy benefits which this technology can be expected to deliver are likely to be higher than the estimates given in Appendix 4.

SageGlass ${ }^{\circledR}$ EC products are made using processes (vacuum coating) similar to those used for spectrally selective low-e and reflective glass today. The ultimate manufacturing cost of SageGlass ${ }^{\circledR}$ windows at maturity will be similar to but slightly higher than that of low-e today ( $\sim 60 / \mathrm{m}^{2}$ non-residential) due primarily to the extra cost of materials-the EC coating is five times thicker than low-e. Independent market surveys of "smart windows" by SRI Consulting and Townsend Research Group LLC support our estimates for market penetration and indicate that they are in fact conservative. SRI's survey predicts the creation of a new $\$ 50$ billion industry with annual sales of $\$ 7.25$ billion (volume of 36 million $\mathrm{m}^{2}$ at $\$ 200 / \mathrm{m}^{2}$ ) into construction window markets alone. Using our more conservative figures, we estimate the creation of over 140,000 new jobs (one direct and three indirect jobs per $\$ 250 \mathrm{~K}$ of sales) to serve the U.S. markets alone, and another $\mathbf{1 0 0 , 0 0 0}$ to support the $\$ 7$ billion export potential. In addition, there will be an investment of \$5 billion in new manufacturing plants and \$350 $\mathbf{M}$ (4\% of sales) in R\&D based on U.S. sales alone.

Publications such as the Wall Street Journal and Inc. magazine have reported the benefits to health and productivity that windows and skylights can provide: When people are exposed to more daylight their productivity increases and absenteeism drops. Use of EC windows eliminates the needs for shades and blinds and allows more light into the work place. One of a number of productivity studies has estimated productivity improvements from better thermal and visual comfort in the $\$ 12-125$ billion range ${ }^{8}$.

\section{Environmental benefits}

There are no wastes other than power generation emissions for either the building glazed with EC glass or that glazed with standard static glazings. The operation of an EC window does not generate waste emissions. Clearly the reduction in energy required to operate the building with EC glass reduces the amount of fossil fuels that need to be burned and therefore the emissions of not only $\mathrm{CO}_{2}$ but other pollutants such as $\mathrm{NO}_{\mathrm{x}}$ and $\mathrm{SO}_{\mathrm{x}}$. Previous estimates based on total national energy savings of 0.71 quads and derived using the generic carbon emission factors of

\footnotetext{
${ }^{8}$ Fisk, William J. "Potential Nationwide Improvements in Productivity and Health from Better Indoor Environments” 1998 ACEEE Summer Study on Energy Efficiency in Buildings.
} 
$15.35 \mathrm{~kg} / \mathrm{MBtu}$ and $15.19 \mathrm{~kg} / \mathrm{MBtu}$ for residential and commercial buildings respectively provided in a recent $\mathrm{NETL}^{9}$ solicitation we estimate a reduction in $\mathrm{CO}_{2}$ production of $\mathbf{1 0 . 9}$ million tons annually. For the typical buildings used in this example calculation, the reduction in carbon emissions would be $\mathbf{1 , 8 0 0} \mathbf{~ k g} /$ year $(119.5$ x 15.19) and $\mathbf{1 , 3 0 0 ~} \mathbf{~ k g} / \mathbf{y r}(83.9 \mathrm{x}$ 15.19) compared to spectrally selective and reflective glazings respectively. In addition, from calculations using NY State's Window technology report (Sept. 95) ${ }^{10}$ we estimate a national reduction in $\mathrm{NO}_{\mathrm{x}}$ and $\mathrm{SO}_{\mathrm{x}}$ production by 38,800 and 15,200 metric tons annually, in addition to 18,500 tons of airborne particulates.

\section{Discussion of Work Performed}

In order to make progress towards some of these goals, the following tasks were carried out. These tasks are aimed at improving the overall quality of the electrochromic devices developed during the Pilot Line phase, by improving the process stability and other aspects of device fabrication. Specific work carried out on these tasks is discussed here.

\section{Task 1: Process Improvement}

In order to place the work done as part of this task in context, it is useful to briefly review the functionality and construction of an EC device.

In this section we briefly describe some of the important concepts concerned with the operation of EC devices. The SAGE EC device is a series of thin films deposited onto a glass substrate one on top of the other to form a stack. This is shown in Figure 3. In order for the window to color and bleach uniformly, it is necessary to deposit all the constituent layers uniformly. It is also necessary to ensure that there are as few defects (imperfections and particles in particular) as possible contained within the stack. In practice this means maintaining a clear focus on the deposition of highly uniform films, and ensuring that the devices are processed in the cleanest conditions possible.

[See Section 1 in Proprietary Appendix].

\subsection{DOE Process Optimization}

Several different areas of the process were addressed in order to prepare the process to be run on our new production coater, which has a fixed number of targets, and does not allow us to make multiple passes beneath any particular one of them. This means that we needed each material to be deposited in one pass on the Pilot Line equipment to simulate production. Experiments were conducted where each of the individual layers was deposited in a limited number of passes in order to try to replicate the conditions we might expect during production.

After this initial series of experiments, the process was transferred to the production equipment. Small variations in the deposition of the films as a result of slight differences in,

\footnotetext{
${ }^{9}$ Referenced in NETL solicitation - Energy Information Administration (EIA/DOE), Annual Energy Outlook, Dec 1998 \& 1999, US DOE; DOE/EIA - 0383(98) \& 0383(99).
}

${ }^{10}$ NYSERDA Window Technology Report, September, 1995. 
for example, machine geometry or heating variations were then accommodated. Finally, a series of designed experiments were carried out in order to optimize the performance of the entire device, using film thicknesses and deposition parameters for each of the films. Results of this series of experiments are described below.

EC: Depositions were carried out at slower linespeeds allowing the films to be deposited in fewer passes. In general, the early results were encouraging, in that the overall film thickness could be obtained by simply slowing the linespeed and reducing the number of passes at the same power. No meaningful difference was seen between devices this way and 'standard' devices. However, it became apparent that there needed to be an increase in the power in order to make the throughput requirements anticipated to happen during the scale-up process.

Further tests at a later date showed that the EC layer could be deposited at higher power, with very little impact on the behavior of devices made using this material. However, it was necessary to modify the method by which the films were deposited, in that both the cathode and power supply were modified from what was used at the Pilot Line stage.

[See Section 2 in Proprietary Appendix].

One further significant result which was obtained during the process optimization of the EC layer was the correlation between the thickness of the EC layer and the number of short circuits - shorts - which are observed in the finished product. It has been determined that a thicker EC layer will lead to fewer shorts in finished devices, and happily, the thickness necessary for a substantial reduction in the occurrence of shorts is compatible with the requirements for obtaining adequate electrochromic performance.

In conclusion, the requirements for the production of an EC layer under production conditions have been satisfied by the development work carried out in this project. The deposition was modified from 6 passes at around 35cpm (cm per minute) at the Pilot Line stage to a single pass at $12 \mathrm{cpm}$, representing an approximate doubling of the deposition rate compared to that achieved at the Pilot Line stage. This has been achieved with no loss in performance of the devices, and no compromise in the uniformity of the layers.

Further experimentation has been carried out to achieve better uniformity for the EC layer. This has included implementation of a three stage heating process, and a flexible gas distribution system to allow adjustments of uniformity to both heating and deposition in 'realtime'. In order to do this effectively, we have developed an in-situ optical transmission monitor which allows the thickness of the layer to be calculated, and fed back to the coater operator to permit real-time adjustment of the deposition parameters. This optical monitor can be configured to measure transmission, and therefore thickness, at a number of points across the coater width, and therefore give an indication of the uniformity of the layer.

In addition, we have invested in an infra-red thermal imaging system which gives us instant feedback of the temperature of the glass immediately prior to coating.

In summary, it was found that one of the key processing variables is the thickness of the EC layer. It is necessary to ensure that the layer is thick enough to provide adequate coloration depth as well as some insulation from shorting defects, but not too thick so that the processing equipment is pushed too far. 
[See Section 3 in Proprietary Appendix].

$C E$ : Again, the first task was to ensure that the appropriate thickness could be deposited under the anticipated production conditions. Testing showed that this was indeed possible, and so devices were manufactured under the anticipated production conditions, which proved to be indistinguishable from other product made around the same time. The process was then successfully implemented onto the production equipment.

Several further improvements have been made since the process was implemented on the Production equipment. In particular, the planar cathode has been replaced with a rotatable cathode in order to increase the target utilization, maximum power and hence deposition rate. Rotation of the target surface through the erosion area is one of the key features of the rotatable cathode. This movement results in the following advantages:

- The entire surface of the target erodes evenly thus resulting in a high degree of utilization of the target material.

- Higher material inventory and more efficient utilization result in target lifetimes 5 - 10 times longer than planar magnetrons

- Target cooling is improved for high sputter power density

The entire surface of the target is sputtered, minimizing build up of dielectric layers that can cause arcing and therefore damage to the target or defects to the coating film.

Furthermore, an in-situ transmission monitor based on LEDs and photodiodes has been installed, and this allows the transmission of the CE to be monitored immediately after deposition. Once again, this is a distributed system, and allows monitoring of the uniformity of deposition, both in the direction of travel as well as across the width of the target. Optimization experiments have been carried out to improve both the uniformity of deposition as well as the overall transmission of the film itself. It has been found that in order to monitor the deposition process itself, the most reliable results are obtained by depositing a layer onto a piece of coated glass, rather than a partially complete device.

[See Section 4 in Proprietary Appendix].

Lithium: As with the other thin film depositions, it was necessary to improve the deposition rate and reduce the number of passes to one to simulate production conditions. This was achieved after a number of experiments, and has proved to be relatively stable.

Once again, an in-situ optical monitor has been installed in order to monitor the depth of charge inserted into the device. This is an identical unit to that installed to monitor the CE deposition, therefore giving transmission data a few minutes after lithium deposition. These data are displayed to the coater operator in real-time, and so can be used to adjust the process for any slight variation which may have occurred.

Several designed experiments have been carried out to determine the optimum level of lithium for the device. The results have largely mimicked those seen on the Pilot line.

[See Section 5 in Proprietary Appendix]. 
Ion Conductor (IC) layer: A significant number of process optimization experiments have focused on rapid development of an improved ion conductor (IC) process. Initially, experiments were done in this area, but a high degree of process variation and limited experimental time resulted in inconclusive results. Later, with improved process stability, and better DOE methodology, we have been able to rapidly demonstrate the feasibility of the new approach.

Briefly, several factors were varied, including the thickness of the IC, and the amount of lithium that was incorporated into the device. Significant variations in the leakage current were seen, and we were able to gain a valuable insight into how the leakage current can be minimized without adversely affecting any other properties.

Top Transparent Conductor (TTC): This was typically deposited in two passes at the pilot line stage, and we have shown that this can easily be done in a single pass with no apparent difference in properties. Experiments have therefore focused on trying to understand the relationships between TTC deposition conditions and final device properties. For example, three runs were done at three oxygen levels in the TTC deposition and two firing temperatures. The results suggested that the lower temperature may give a more optimal combination of bleached state transmission (and color) and TTC resistance.

As a result of a series of designed experiments the TTC layer was modified slightly by addition of an optical tuning layer. This allowed the overall transmission to be increased slightly, and the transmitted color shifted slightly into the green, with no degradation in the dynamic performance.

Conclusion: Design of experiment techniques have been used to determine the optimized processing conditions for the deposition of the SageGlass ${ }^{\circledR}$ EC device. These have been used primarily to transfer the process from the Pilot Line, where deposition was carried out at a variety of linespeeds using multiple passes under individual targets, to the Production facility, where the linespeed is a constant, and therefore all the deposition processes need to be capable of depositing the required thickness in a single pass. This needs to be done without significantly modifying the individual film properties, or producing additional non-uniformities in the films. This has been robustly demonstrated, and devices with excellent properties surpassing those made at the pilot line stage have been produced.

The next phase of development was aimed at improving the yields for each process, basically utilizing two different approaches. First, techniques will be developed which will enable otherwise scrap devices to be salvaged by a rework process, and second, to concentrate on a general improvement in the overall process quality and repeatability. One of these approaches forms the subject of the following section.

\subsection{Minimize Shorting Defects}

Common seen in thin film EC devices are known as shorts. These are defects which cause an electrical bridge between the top and bottom transparent conductor, and can originate from a variety of sources. 
Dependence of number of shorts per unit area on EC layer thickness

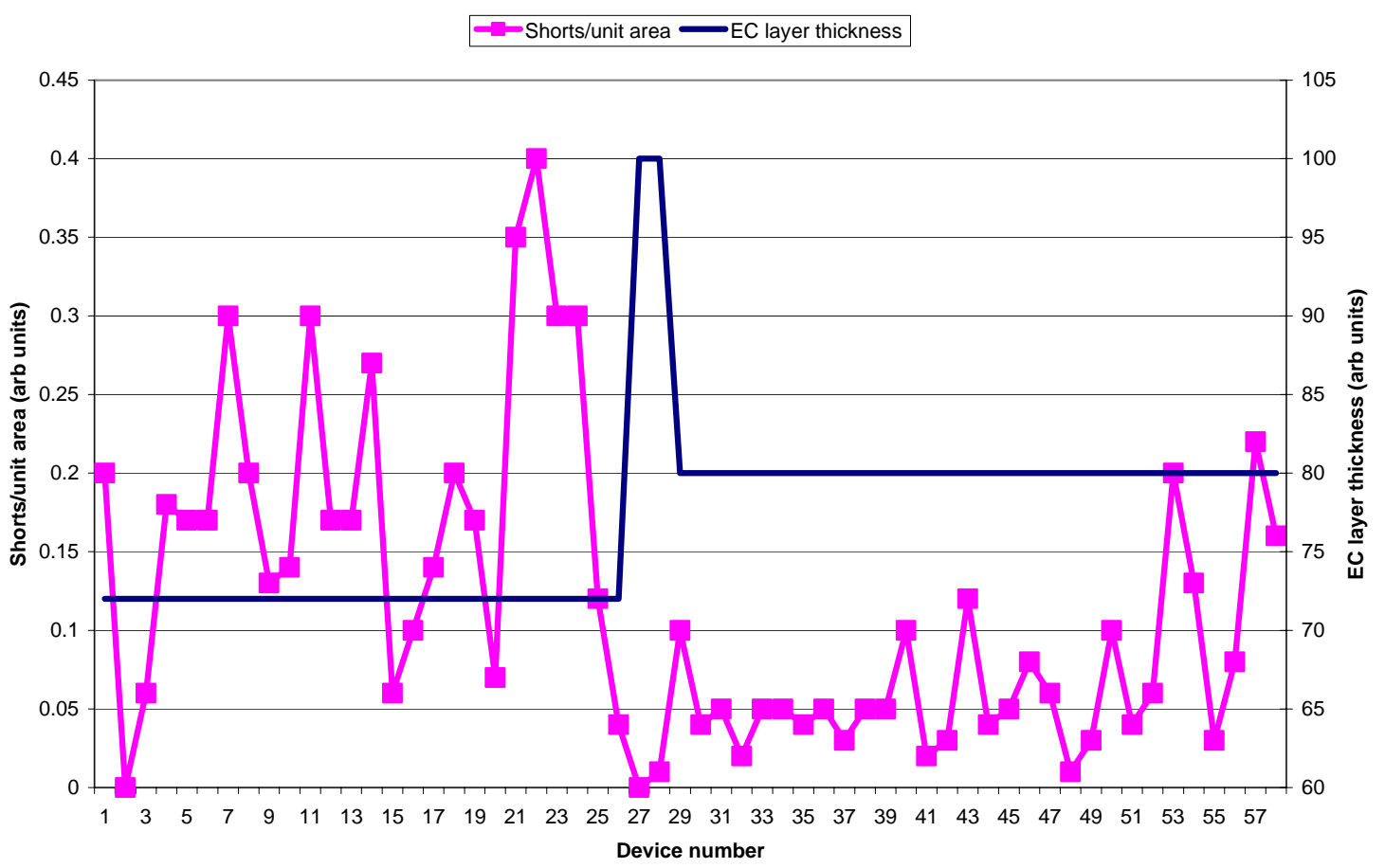

Figure 4 - Dependence of number of shorts per unit area for a particular device size as a function of EC layer thickness. There is a fairly clear dependence observed, particularly for the two device produced with the very thick EC layer.

There are therefore two methods of approaching the task of minimizing shorting defects: first, identify and eliminate possible causes of the defects themselves, and second, determine a method of cleanly removing the defect origin after the device has been completed.

Furthermore, it may be possible to tailor the process to minimize the probability of inherent defects manifesting themselves as shorts. Experiments previously reported have shown that certain layer thickness can have a substantial effect on the number of shorting defects seen. In particular, we have seen on more than one occasion that increases in the thickness of the EC layer - of the order of $20 \%$ more than out nominal thickness - gives a significant reduction in the number of shorts observed on finished devices.

In order to understand the origins of shorts, microscopic inspection of all shorts detected at first coloring is carried out. This involves isolating the short and inspecting it to determine the cause. This allows us to characterize which areas of the process are responsible for the defect causing the short and therefore allows us to concentrate our efforts on eliminating the cause from the process.

SEM/EDS analysis of shorts coupled with observations and experiments conducted in the sputter coater helped to reveal root cause for some of these defects. A discussion of some of the analytical work carried out to minimize shorting defects is given in Section 6 of the 
Proprietary Appendix. As part of our program of continuous improvement, defect root causes are identified with follow-on work to minimize or eliminate their occurance.

\subsection{Six Sigma Training/Quality}

During the project, selected members of the SAGE team were trained in the techniques of 6sigma to improve the overall approach to quality in the production of EC windows. Some details of this training are discussed below. Several of the techniques which have been incorporated into SAGE standard operating procedures are discussed below.

All new employees receive an 'Introduction to Quality' training course, which is a series of sessions amounting to between 8 and 10 hours of targeted training. In addition, Design of Experiments (DOE) training is continuing for all new employees involved in technology development.

One engineer took training on calibration control system design and as a result developed the calibration system for the production facility. Two engineers took training on software to control our engineering drawings and prints in support of our document control system. Our Document Control System was designed in the first quarter of 2004.

Key technical and operations personnel were trained on using the SPC, FMEA and DOE tools from 6-Sigma. The entire organization was trained in Value Stream Mapping, a Lean-Sigma tool that will improve flow, reduce handling and help SAGE do a faster job of identifying and signaling critical yield issues in the process. Teams were set up to study and implement Kanban signaling and flow in the factory operations. Indeed, the complete factory planning operation was turned over to this team, and the layout and process flow was designed using Kanban and lean operating procedures.

The techniques of 6-sigma which have been studied and absorbed into the working practices of the company have been applied in many different areas. An outline of some of the uses is given below.

One of the primary quality focuses has been to ensure proper calibration and measurement reliability and repeatability of key process control measurements in our deposition process. The primary areas of focus included gas-flow and gas pressure measurements, and carrier line speed calibration. Experiments were conducted on carrier line speeds that indicated variation beyond that which would be considered normal for such a process. It transpired that the cause was due to a noisy output signal from the PLC, so modifications were made to replace the PLC output with a completely separate control source, which has resulted in significantly better line speed control. Periodic measurements are conducted to qualify the line speed accuracy, and a permanent calibration procedure is pending.

Each sputter process zone has independent sensors to monitor the gas-flow, and the pressure of the process gas. A rigorous calibration schedule was developed, and potential design changes were made to achieve greater uniformity, both across the process zone, and from run-to-run.

An evaluation was also made of our clean-room operations, and a variety of steps were identified to reduce sources of particulate contamination. An example of the modifications was a change in the clothing worn by the personnel working in the clean-room, from a simple hairnet, to a complete head covering. Additionally, SAGE invested in particulate monitoring 
equipment that is now in use to monitor the cleanliness levels of our clean room operations. Lower particulate counts will directly impact process yields.

SPC techniques are being implemented in all areas of the process operation, from glass cutting (geometrical size, angular distortion), through tempering (glass bow), thin film thicknesses and optical properties, to device testing and IGU fabrication (IGU sizes and thickness).

In conclusion, several techniques dedicated to improving the quality of manufacturing processes have been implemented successfully.

\section{Task 2: Rework}

\subsection{Develop Repair Technology}

The second approach to minimization of shorting defects is the removal of the defect source after the device has been completed and tested. At the pilot line stage, equipment utilizing spark erosion repair for shorts was developed and was used at monolithic test with good results.

The original proposed objective was to design and build a stepper motor driven XY stage and to develop an algorithm to locate the centers of electrical short defects. This would be used in conjunction with micro spark erosion for excising electrical short defects. An XY stage was built with a short finding algorithm, but it was found only to work on large well defined shorts. The XY stage was sufficient at the time it was built, but as throughput increased and device specifications tightened, the use of the XY stage took too much production time and was not as good as the human eye at detecting all types of shorts. However the micro spark erosion technique of excising shorts was found to be a very useful tool with manual rework and was developed further.

The main issues with spark erosion rework are the size of the cleared area and whether the reworked area becomes leaky during product screening. Reworked areas have missing or no films and hence do not color in and then appear as a non-coloring dot, ideally the diameter of the reworked area should be equal to or less than 300 microns. Also, the reworked area can become leaky after the initial rework attempt and may need to be reworked again, or the area can become leaky in the future and in essence become another short which cannot be electronically reworked after IGU fabrication because the films are now inside the IGU.

Initial testing was done with an in-house designed and built spark generator, with further testing done with an off the shelf electric pulse generator. The adjustable parameters for the pulse generator are voltage, frequency, pulse width, and number of pulses. Initial feasibility tests were done to achieve a setting where the initial rework was not leaky. Once a decent setting was found, a range finding DOE showed that the important variables were voltage and number of pulses.

A simple matrix was set up using four small devices measuring rework size and number of leaky reworked areas. Twenty spots were reworked on each device. The results are given in Table 4 below.

It appears that with these parameters leaky reworked areas are not a concern and the size range looks desirable. 


\begin{tabular}{|l|l|l|l|l|}
\hline $\begin{array}{l}\text { Voltage } \\
(\mathrm{V})\end{array}$ & $\begin{array}{l}\text { Number } \\
\text { of pulses } \\
(\#)\end{array}$ & $\begin{array}{l}\text { Size of } \\
\text { cleared } \\
\text { area } \\
\text { (microns) }\end{array}$ & $\begin{array}{l}\text { Initial } \\
\text { number } \\
\text { of leaky } \\
\text { RW area }\end{array}$ & $\begin{array}{l}\text { Number of } \\
\text { leaky RW } \\
\text { area after } \\
\text { screening }\end{array}$ \\
\hline 60 & 100 & $200-250$ & 0 & 0 \\
\hline 60 & 400 & $250-300$ & 0 & 0 \\
\hline 100 & 100 & 300 & 0 & 0 \\
\hline 100 & 400 & $300-350$ & 0 & 0 \\
\hline
\end{tabular}

Table 4 - Experimental data from rework experiments

In another experiment, a pair of devices were reworked using a setting of $100 \mathrm{~V}$, and 400 pulses (the highest setting was used initially because the cleared area size range is the same as what is observed with the current system). Neither of the two device had any leaky reworked areas. Later testing included reworking more devices with the pulse generator to build up a statistical history and lowering the voltage and number of pulses to get the smallest reasonable cleared area possible. This resulted in equipment which has been used in production for removing shorts, and a typical erosion pattern is shown in Figure 5. In this case, the reworked damage area is of the order of 300microns in diameter, which is on the verge of being visible to the naked eye, especially when the device is in the colored state, thereby giving a high contrast between the defect and the colored device.

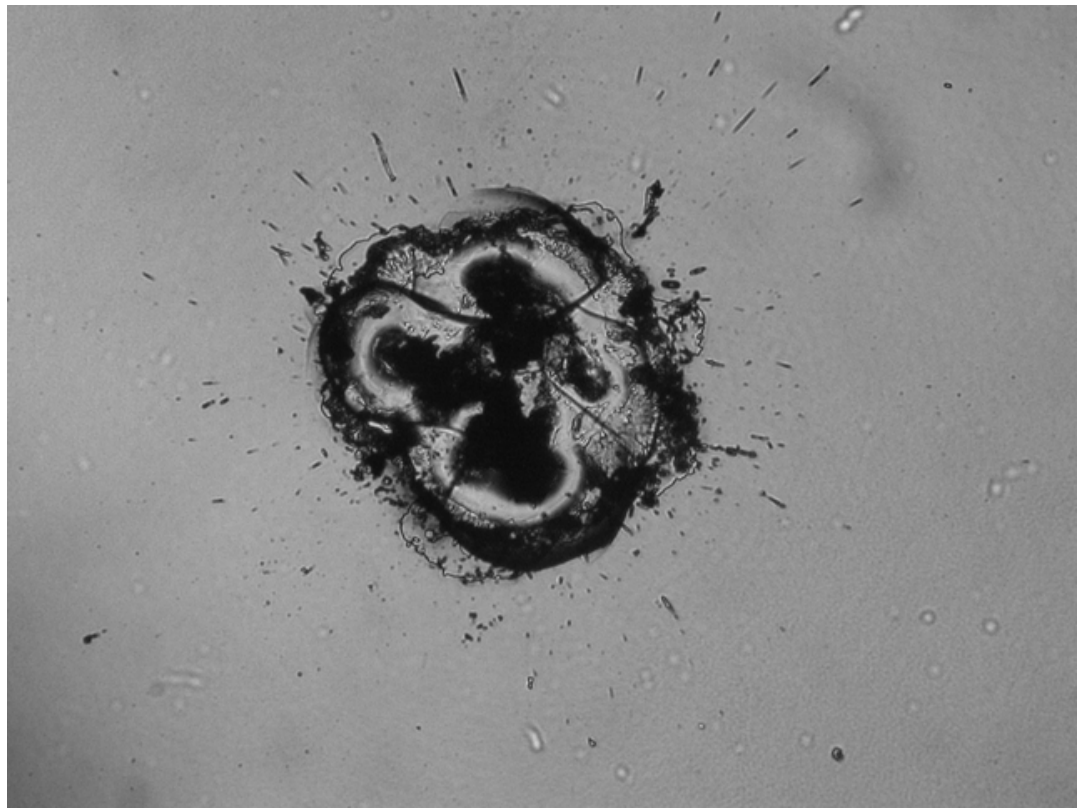

Figure 5 - Typical residual damage seen after micro spark erosion rework 


\subsection{Develop Semi-Automated Equipment}

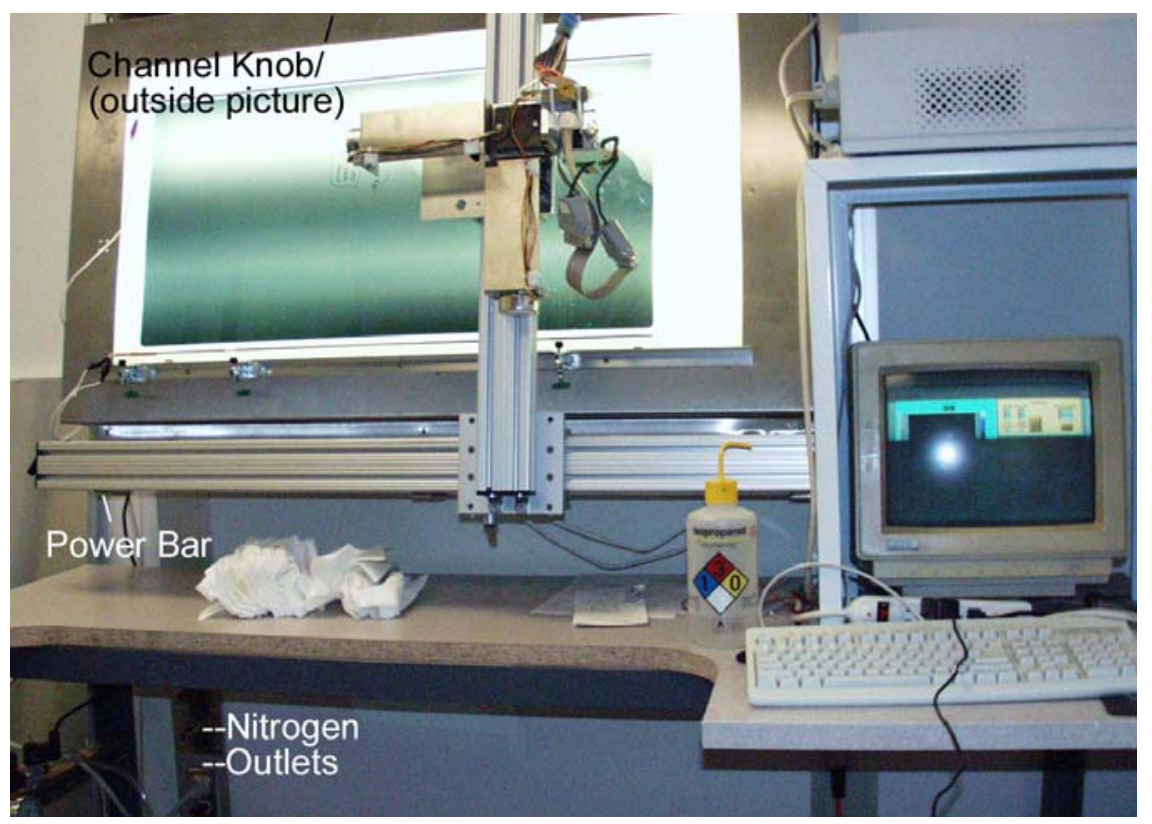

Figure 6 - A photograph of the automatic rework station developed during this project.
Given the difficulty of accurately locating and removing a short using a handheld probe, an automatic rework station was designed and built. This equipment was based on an 8x8 grid of pins which were placed in contact with the films near the short, as the device was being colored. The voltage at each pin was sensed, and therefore the voltage distribution could be determined as a function of position. Given knowledge of the voltage distribution, it is possible to determine the location of the short, as

this will be at the voltage minimum. It is then possible to use one of the pins - the one closest to the minimum in the potential distribution - to apply a potential which will destroy the short.

The sensing head, as described above was constructed and mounted on an x-y stage, which is turn was mounted on a backlight. This arrangement is shown in Figure 6. The electrochromic device can be seen mounted vertically on the backlight with the films facing outwards. The xy stage has the sensing head and associated electronics mounted on it. The electronic control box is visible at the top right, above the computer monitor. The PC is used to control the whole system, using a custom LabView program written in house, the front panel of which is shown in Figure 7. 


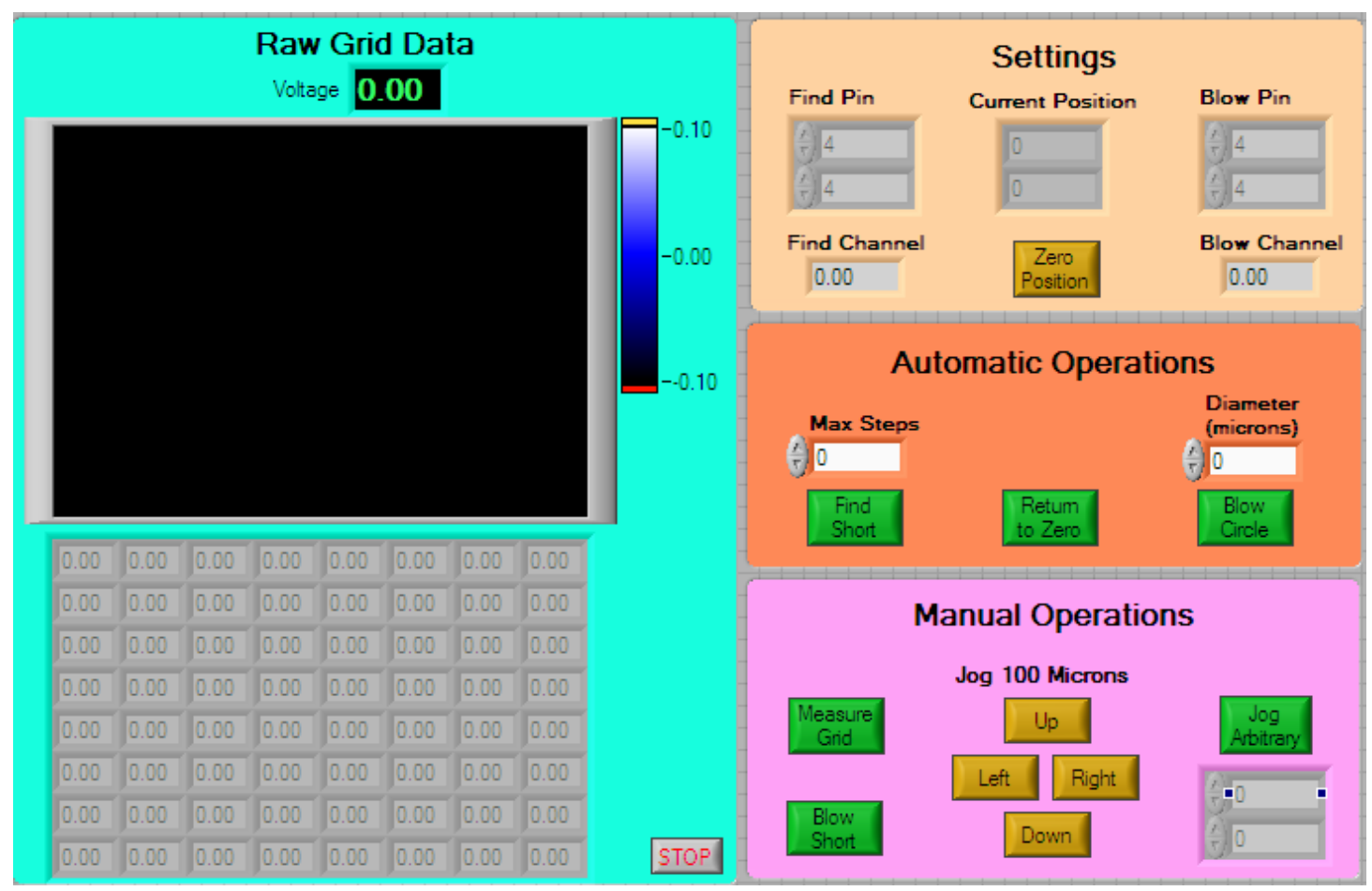

Figure 7 - Custom developed front panel for the automatic rework station

The left hand side of the figure provides a display showing an image of the voltage distribution, as well as details of the voltages measured at each pin. The right hand side shows the controls which the user can activate to jog the position of the probe, or blow the short.

The equipment was shown to work reasonably well, although it was not without some issues. First, it only worked really well for relatively large shorts, as the smaller shorts are more difficult to locate and exercise. This meant that the shorts which could not be located in this manner had to be reworked manually anyway.

Next, it was rather awkward for the operator, as the devices were tested on a separate tester, this time with the films face down. Shorts and other defects were then marked on the back of the glass. In order to transfer to the rework station, the glass had to be disconnected, flipped over, moved to the rework station, reconnected and re-colored. This proved to be a very time consuming process, but more significantly offered the possibility of causing handling damage to the device.

At the time the rework station was being developed, it was thought that all the shorts would be reworked at the monolithic stage, and there would therefore be no requirement to rework shorts in an IGU. However, it became clear that it was going to be necessary to rework shorts inside of an IGU. The automated rework station as developed here is clearly incapable of performing such an operation. For these reasons, this approach to automated rework was abandoned in favor of a laser based system. 


\subsection{Test Repair Effectiveness}

As has been described above, the automated rework station was developed and was used for reworking a number of devices, albeit with the limitations discussed. It was found that fairly big shorts could be found and eliminated semi-automatically.

However, some fraction of the repaired devices were still seen to generate leaky reworked areas during durability testing. Most of the repaired shorts are only leaky during the time when the windows are bleaching, but the larger concern is that a small fraction are becoming leaky when the device is held in the colored state, which is a reason for scrapping a device. Inspection of the reworked site suggested a rather inaccurate and random removal of the thinfilm material, suggesting the spark erosion system needed to be significantly upgraded, or a different, more accurate, method needed to be developed. It was therefore decide to investigate a laser repair system, which potentially offered the added benefit of enabling short repair after a device has been fabricated into an IGU.

As mentioned previously, SAGE device rework has two separate components, that is, monolithic devices, and Insulated Glass Units (IGUs), where the electrochromic device is sealed into a unit with a spacer and another pane of glass. While the spark discharge repair techniques used at the monolithic test stage were relatively successful, it was apparent that these cannot be used after the device has been fabricated into an IGU. Laser process evaluations were therefore conducted with the beam incident from the glass side, opposite the electrochromic film stack. Evaluations were run with fundamental (1024nm), frequency doubled (532nm), and frequency tripled (355nm) Nd:YAG and Nd:vanadate lasers. In each case the electrochromic film stack was successfully removed.

Given the requirements for reworking devices after they have been fabricated into an IGU, and the relative lack of accuracy in the placement of the manual system, the spark discharge approach is being phased out in favor of the laser based system.

\section{Task 3 Laser Patterning}

As-received substrates are coated with a transparent conductive coating, onto which are patterned conductive metallic electrodes. In order to prevent these electrodes from being shorted together via the conductive coating, the coating must be patterned to prevent this. At the Pilot line stage, a microblast sandblaster was employed which removed the conductive coating simply by abrasion. However, this has obvious drawbacks in terms of defect generation due to errant blast media, and leads to a somewhat ragged line. This task was therefore intended to identify and develop a laser based non-contact system for removing the coating cleanly and neatly.

\subsection{ID Laser system and Develop Process}

The basic parameters of a laser patterning process are: laser wavelength, pulse width; pulse overlap, pulse energy; repetition rate; and achievable beam spot diameter. The YAG family of lasers is of greatest interest for this project because the light from these lasers is only weakly absorbed in silicate glasses, and they are available in robust, industrial grade configurations. Factors other than the wavelength - which is largely determined by selecting a YAG family 
laser - such as pulse width, had to be determined, and was done by a series of experiments by laser system vendors.

Spectroscopic absorption measurements were made on various combinations of films comprising a SageGlass ${ }^{\circledR}$ electrochromic window, to determine which laser wavelength would be most effective for device isolation. The criteria included high absorption in the transparent lower conductor, low absorption in the float glass substrate, and a high ratio of absorption in the transparent coating to that in the glass. Measurements were taken near the wavelengths of Nd:YAG fundamental (1064 nm), frequency doubled (532 nm), and frequency tripled $(355 \mathrm{~nm})$ beams, available in a wide variety of industrial lasers. The results are shown in Table 5.

These results indicate that the frequency doubled YAG output at $532 \mathrm{~nm}$ is the preferred source for TCO removal, because of the high TCO:glass absorption ratio. This is due to the very low absorption in the glass, rather than to high absorption in the TCO.

It is interesting to note that an increase in absorption of the glass of $0.1 \%$, to $0.3 \%$ overall would result in a ratio of 27:1, very similar to that for the other two wavelengths. It is interesting enough to add the frequency-doubled beam into the mix of lasers under consideration. There does not therefore seem to be a strong reason to choose between the beams on the basis of absorption, for this application, until we can verify the range of absorption we are likely to observe for different glass samples.

\begin{tabular}{|c|c|c|c|c|}
\hline$\lambda(\mathrm{nm})$ & $\begin{array}{c}\text { Absorption: } \\
\text { Glass only }\end{array}$ & $\begin{array}{c}\text { Absorption } \\
\text { TCO + glass }\end{array}$ & $\begin{array}{c}\text { Difference: } \\
\text { (TCO+glass) } \\
- \text { (glass } \\
\text { only) }\end{array}$ & $\begin{array}{c}\text { Ratio: } \\
\text { Absorption } \\
\text { TCO/(glass } \\
\text { only) }\end{array}$ \\
\hline 1060 & $1.3 \%$ & $32.2 \%$ & $30.9 \%$ & $24: 1$ \\
\hline 530 & $0.2 \%$ & $8.5 \%$ & $8.3 \%$ & $42: 1$ \\
\hline 355 & $1.2 \%$ & $33.0 \%$ & $32.1 \%$ & $26: 1$ \\
\hline
\end{tabular}

Table 5 - Absorption of various YAG laser wavelengths in some of the SageGlass ${ }^{\circledR}$ films.

Pulse width is the parameter that most directly controls the amount of heat carried off by the ablated material versus the amount of heat transferred into the substrate. The shorter the pulse, the less heat is conducted into the substrate. It is now thought that substrate heating is undesirable.

The other parameters - pulse energy, pulse overlap and repetition rate - primarily determine the rate at which a structure such as an isolation line can be formed. This is of prime interest in determining capital and operating costs of a laser patterning system, given specific throughput requirements. 
Several lasers were evaluated to determine suitability for laser patterning of the transparent conductor. As suspected, the long wavelength, slow pulse, 1064nm laser produced large heat affected zones (HAZ), characterized by crazing of the underlying glass substrate and high electrical leakage currents along laser scribed lines. The Q-switched green laser produced very low leakage scribe lines, and no visible crazing. Previous tests with a Q-switched $1064 \mathrm{~nm}$ laser (exact pulse width unknown, but typically tens of nanoseconds) also showed leakage problems, but no crazing, demonstrating that the longer wavelength and greater pulse width are each problems, but in different ways. We are therefore concentrating our efforts on the 532nm green, Q-switched lasers. The choice of YAG or vanadate hosts needs to be based on the required repetition frequency, and this is now being evaluated.

A diode-pumped, Q-switched, frequency doubled (523nm) Nd:vanadate laser, with pulse widths of 10 nanoseconds, operating at $20 \mathrm{kHz}$, was ultimately chosen as the favorite.

The laser was purchased and integrated into a system which would allow semi automated operation. Briefly, the raw glass is cut to size, the sharp edges are removed, and an identifying bar-code etched onto it. It is then washed, and by virtue of the identifying barcode, the size of the piece automatically generated by look-up in a central database. This allows the $x-y$ control to be driven accurately allowing the laser line to be scribed the full length of the glass, but no further. Even if the laser did run over the end of the glass, it would be sufficiently defocused so it would not significantly damage the table. 


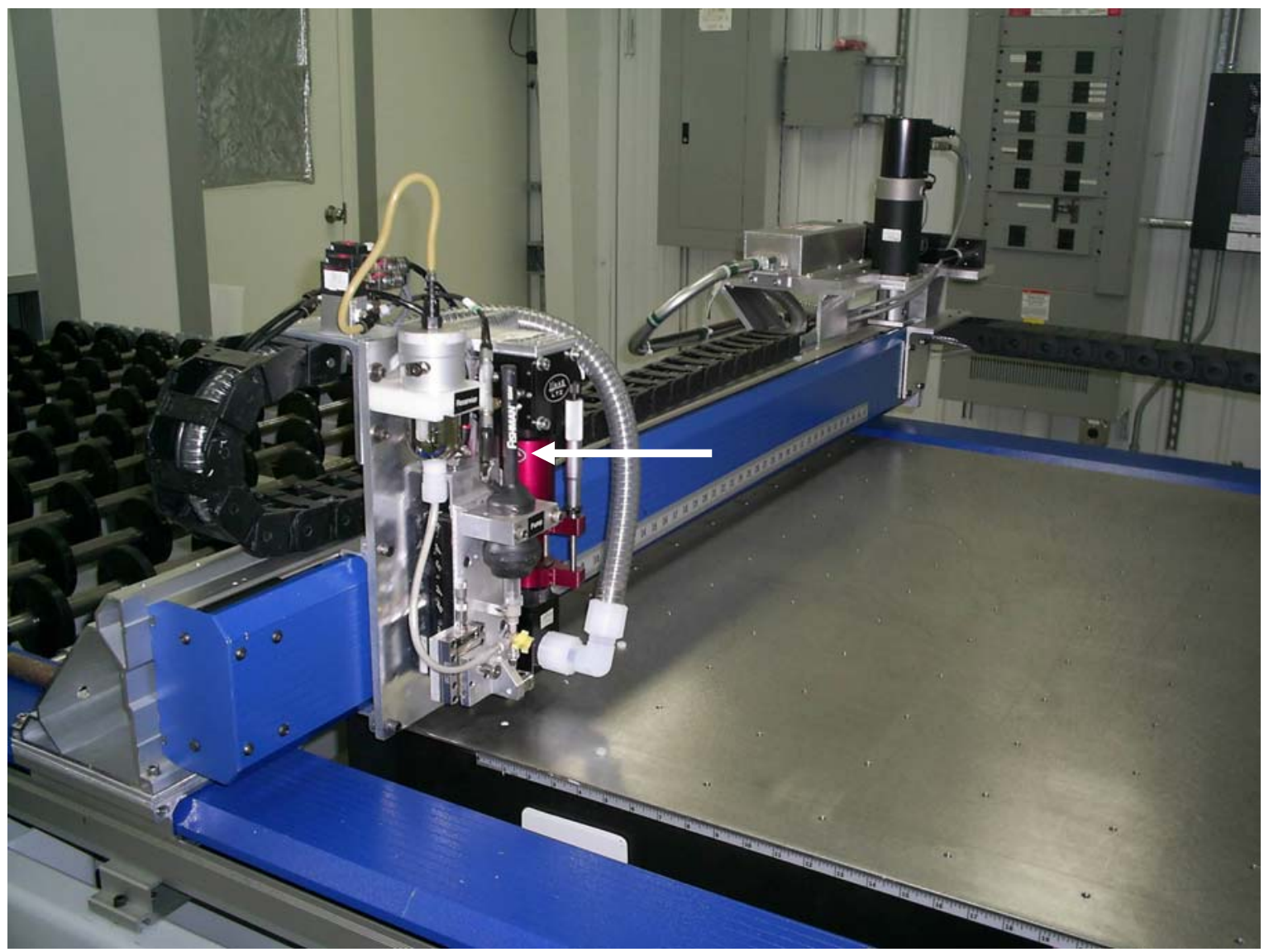

Figure 8 - Photograph showing the equipment developed for laser scribing the conductive substrate.

Figure 8 shows a photograph of the equipment developed in house for laser scribing the conductive substrates. This function has also been combined with deposition of the conductive bus bars, as these two operations are required to be performed consecutively, and use the same registration coordinates.

The system is based on an optical table which has been converted so that a vacuum can be applied to the underside of the glass, thereby holding it in place. It is registered using some plastic pins, which ensure accurate placement of the glass relative to the laser. The $x-y$ table consists of a flying gantry, providing motion in the x-direction, onto which the laser is firmly mounted. This gantry also has the flying mirror which moves in the y-direction, allowing variable positioning of the laser cut relative to the edge of the glass. The whole system is integrated into the production line, so that glass is received from the washer, and sent on to the tempering furnace.

The laser is mounted on the far side of the movable gantry, and is visible as an aluminized box with a silver colored connection. Immediately next to this is mounted a mirror arrangement which is used to deflect the beam over to the 'flying mirror' mounted at the near side. This mirror is used to deflect the laser downwards through some further optics, which focuses the beam onto the surface of the glass. The optics are visible in the photograph as they are contained in the red colored tube indicated in the figure by an arrow. The micrometer attached 
to the same tube is used for adjusting the focus in order to accommodate different thicknesses of glass. The semi-transparent hose, connected to the exit end of the laser optics via an ' $\mathrm{L}$ shaped' plastic coupler is used as a vacuum suction tool to remove any ablated debris. This is to prevent any possible contamination from these small particles later in the process.

The operation of the equipment is controlled by another in-house developed software program. The operator simply needs to know the size of the sample being processed, and dimensions are then derived from a central database. The laser then cuts the line isolation automatically, and the resistance across the line is checked to ensure complete isolation. A failure to isolate is very rare, occurring in around $1 \%$ of cases, and this is almost always caused by the laser being out of focus. Those samples which are detected as being not isolated are simply cut again, which always ensures isolation.

One further benefit of laser scribing the line isolation over sand ablation is that of a potential reduction in leakage current. It was determined that the sandblasted line isolation could account for several mA of leakage current, presumably due to inconsistent coverage of the poorly defined step where the films had been removed. It is difficult to ascertain whether the laser isolation is directly responsible for any of the reductions in leakage current for devices made in the production system, compared with those produced on the pilot line equipment, as there have been several improvements to the process which are anticipated to give reductions in leakage current.

In summary, the laser isolation system has been designed, built and software developed to control it. This task is considered a complete success, as the equipment is currently used in production, and is performing entirely satisfactorily.

\section{Task 4 Durability Testing}

Several hundred windows have been fabricated using the techniques developed in the project. Briefly, the substrates are cut to and washed, and then the laser scribed line isolation made. The electrochromic layers are then deposited using standard thin film techniques. The devices are then tested by applying a coloring voltage and measuring both the optical and electrical response. Any shorts which are present can then be reworked using the electrical rework station discussed in Task 2. The windows are then fabricated into an insulated glazing unit (IGU) which entails sealing the films into a double pane unit with an appropriate gas fill, and then making electrical connections to the bus-bars. The devices are then considered to be windows.

These windows are all subjected to an initial cycling protocol, referred to as burn-in, which is intended to weed out any infant-mortality defects. This cycling protocol consists of fully coloring and fully bleaching the window approximately 700-1000 times. This process takes approximately one week to complete and is referred to as room temperature screen. A subset of these devices is then subjected to a further cycling regime, but this time at an elevated temperature and under the equivalent of one sun illumination, a process referred to as solar soaking.

The windows are then tested - either after room temperature screening, or solar soaking - and any performance characteristic changes noted. Any additional shorts which have developed during the cycling process can then be reworked, and the product then shipped to the customer. 
Several samples were constructed and sent to NREL in order to carry out accelerated testing. The results demonstrated the outstanding performance and cyclic durability of three, dual pane, 10.25" x 12", electrochromic IGU windows (NREL ID\#s E11, E12, E13). These electrochromic windows successfully survived over 80,000 cycles of accelerated environmental durability testing under ASTM Test Standard E-2141-02 requirements. This stringent standard is designed to evaluate the combined degradative effects of elevated temperature, solar radiation and extended electrical cycling (50,000 cycles). These windows have far exceeded the ASTM cycle requirement by 30,000 cycles. The testing was performed in NREL's Atlas XR-260 large component environmental test chamber, which provides elevated temperature and simulated solar irradiance using four 6500-watt Xenon lamps under low relative humidity conditions (2 to $9 \%$ ). The EC windows were repeatedly switched between their bleached and deeply colored states while exposed to a 1.1 sun equivalent of an AM 1.5 solar spectrum. In this controlled environment, the temperatures of the windows averaged $\sim 89{ }^{\circ} \mathrm{C}$ for 54,000 cycles and $\sim 72^{\circ} \mathrm{C}$ for the final 26,000 cycles (the temperature was decreased to accommodate the testing of another Sage EC device).

After $\sim 80,000$ cycles of testing, the EC windows retained their original bleached state transmittance (56 to 63\%), and with 600sec. of applied voltage they still color to a uniform dark blue/gray with photopic transmittance ratios ( $\left.\mathrm{T}_{\text {bleached }} / \mathrm{T}_{\text {colored }}\right)$ well in excess of 5.0. In overall perspective, all three windows exhibited remarkable durability and continued to function with high bleached state transmittance, high photopic transmittance ratio or dynamic range, little change in electrical characteristics, and relatively good visual appearance devoid of any major cosmetic irregularities. Digital photos of the windows in their fully bleached and colored condition are shown in Figure 9 and Figure 10. As a relative measure of achievement, 80,000 cycles are equivalent to switching a window seven times per day for 365days/year across a 30-year lifetime. As a result of these tests, the scientists at NREL concluded that scale-up and deployment of this thin-film, solid-state, EC technology into commercial and residential building windows could result in substantial energy savings for the consumer and for the country. 


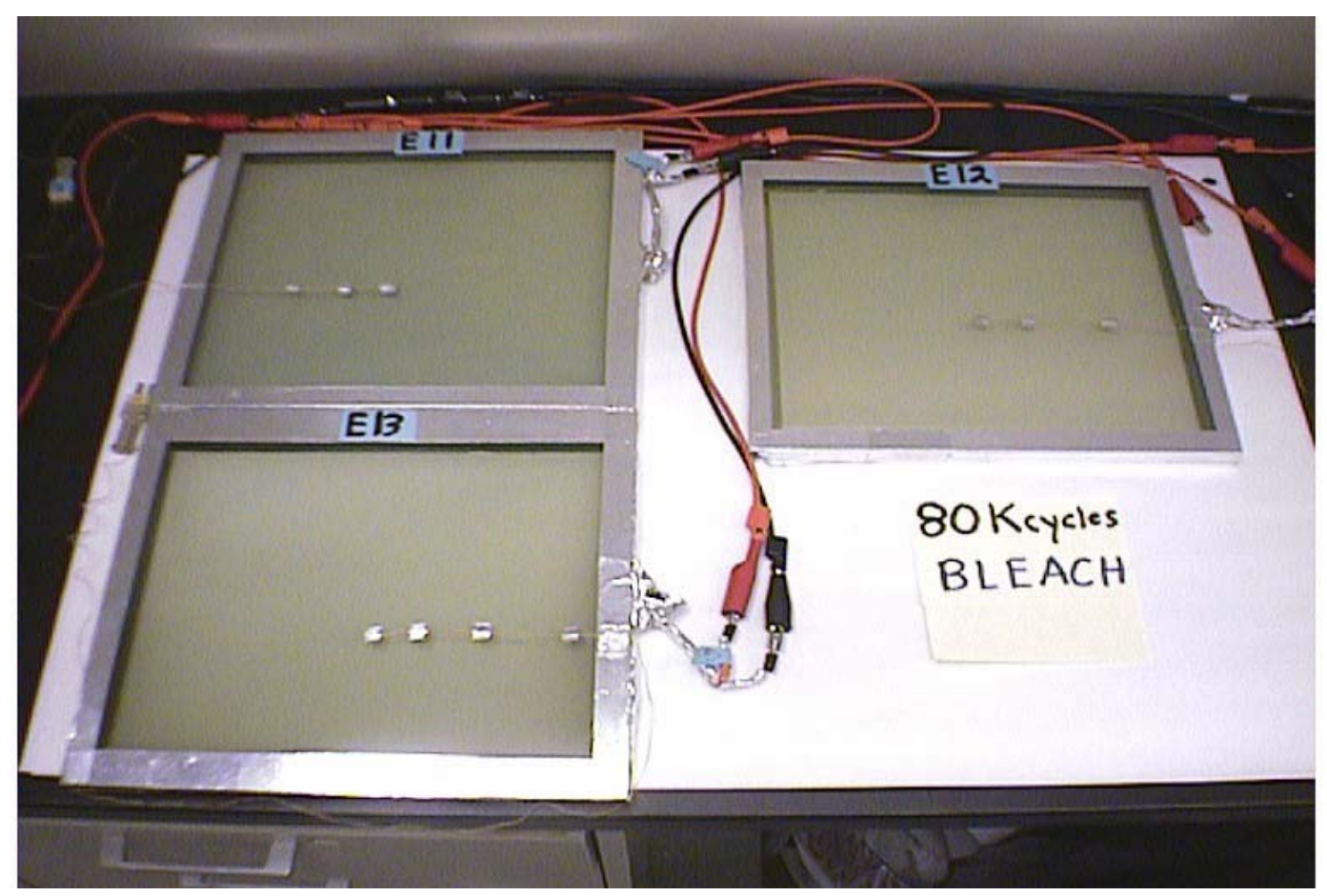

Figure 9 - Images of the devices tested at NREL in the environmental test chamber in the clear (or bleached) state.

SAGE's sample numbers are cross-referenced to NREL I.D. numbers (1J36-8 is E11; 1J39-1 is E12 and L8B-13-2 is E13). Prior to insertion in the XR-260 chamber, the devices were electro-optically characterized at room temperature and $85^{\circ} \mathrm{C}$ using electrical protocols agreed upon by NREL and SAGE. Cyclic environmental testing of these devices was accomplished using methodology outlined in ASTM standard E2141-02. 


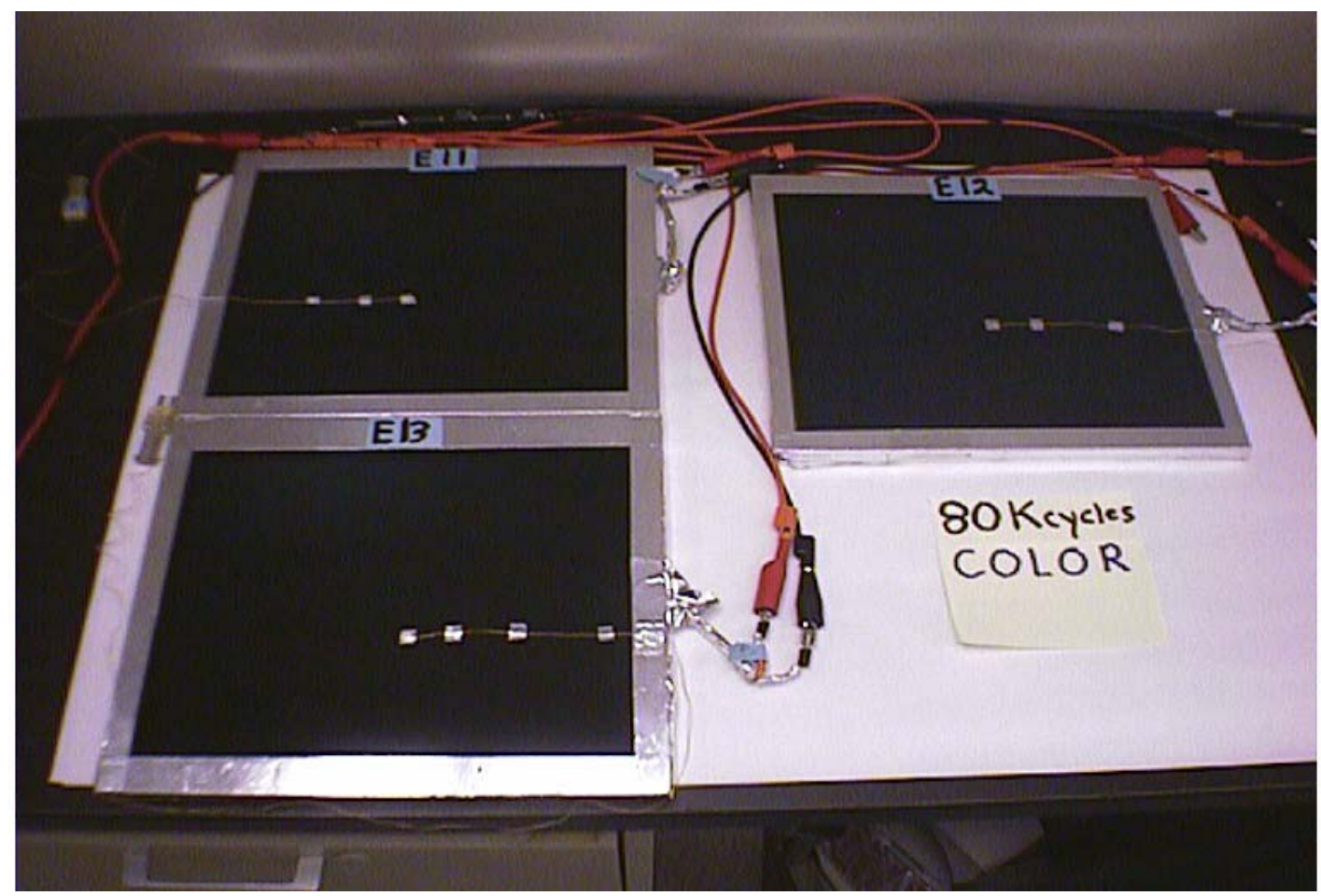

Figure 10 - Images of the devices tested at NREL in the environmental test chamber in the colored state.

\section{Test Conditions and Procedures:}

NREL's Atlas XR-260 large component, environmental test chamber shown in Figure 11, provides simulated solar irradiance using four $6500 \mathrm{~W}$, water-cooled, long-arc xenon lamps mounted in the ceiling above a height-adjustable 4' $\times$ 6' sample plane. The xenon lamps are spectrally filtered (CIRA inner filter, soda lime outer filter) to provide precise solar cut-on and an excellent spectral match to an air mass (AM) 1.5 global solar spectrum from 300 to $800 \mathrm{~nm}$. At longer wavelengths, the fit to the solar spectrum is compromised by xenon emission lines, which are unimportant for our test purposes because they generally do not contribute to photoinduced degradation. Figure 12 shows the typical xenon lamp spectra as compared to an AM 1.5 global solar spectrum. Prior to the start of this test, new xenon lamps were installed; the sample plane was optically remapped; and the XR-260 electronic controls were recalibrated. 


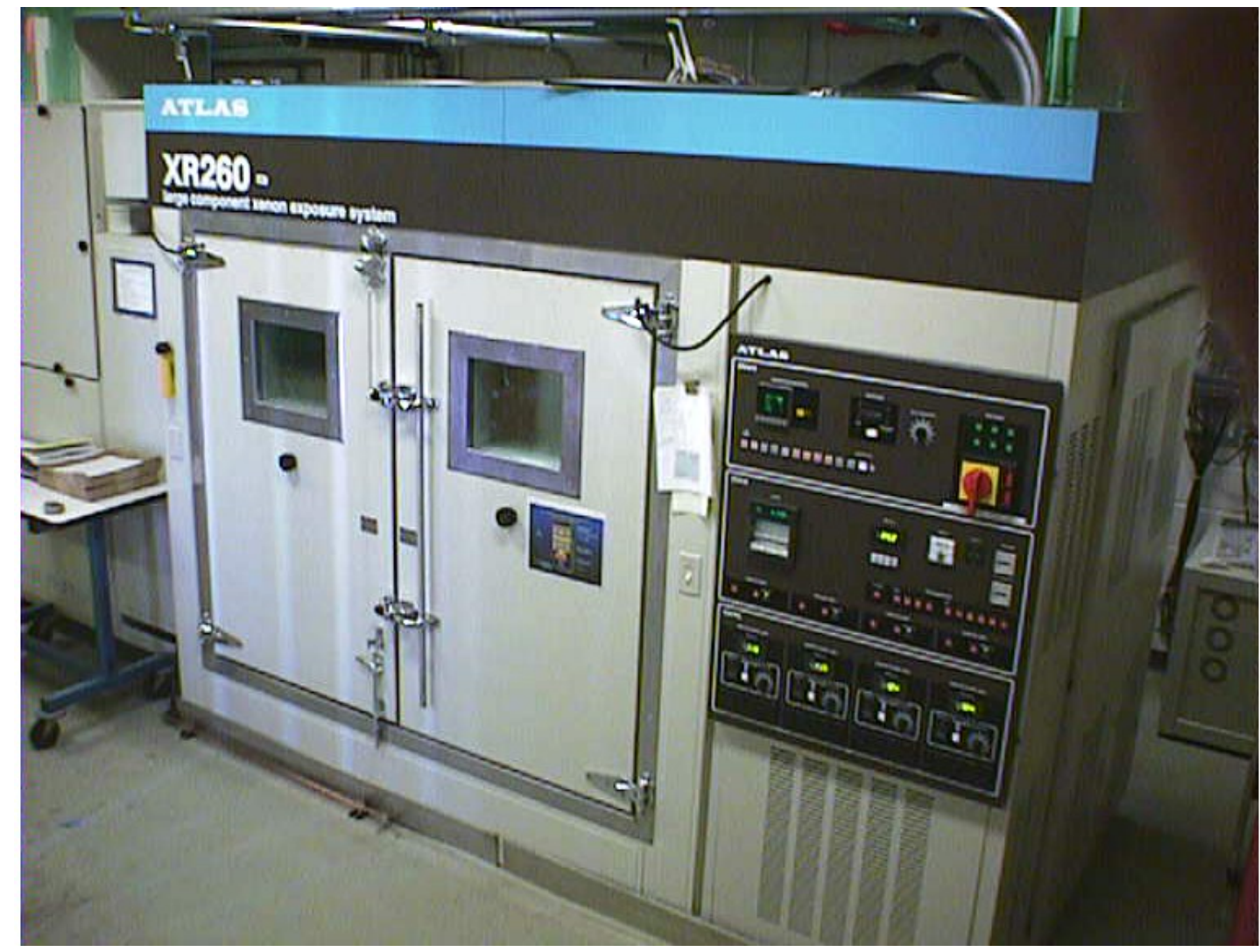

Figure 11 - NREL's Atlas test chamber

In this test we used the following experimental settings in the XR-260 under manual control to achieve the nominal sample temperatures and a 1.1sun equivalent of an AM 1.5 global solar spectrum:

- Dry bulb temperature $(\mathrm{DBT})=35^{\circ} \mathrm{C}$

- Lamp Power $=5.8$ to $6.6 \mathrm{~kW}$

- Irradiance at 340nm $=.120 \mathrm{~W} / \mathrm{m}^{2}$ (for each lamp)

- Sample plane height $=78.2 \mathrm{~cm}$

- Relative humidity $=6$ to $9 \%$ (ambient) 


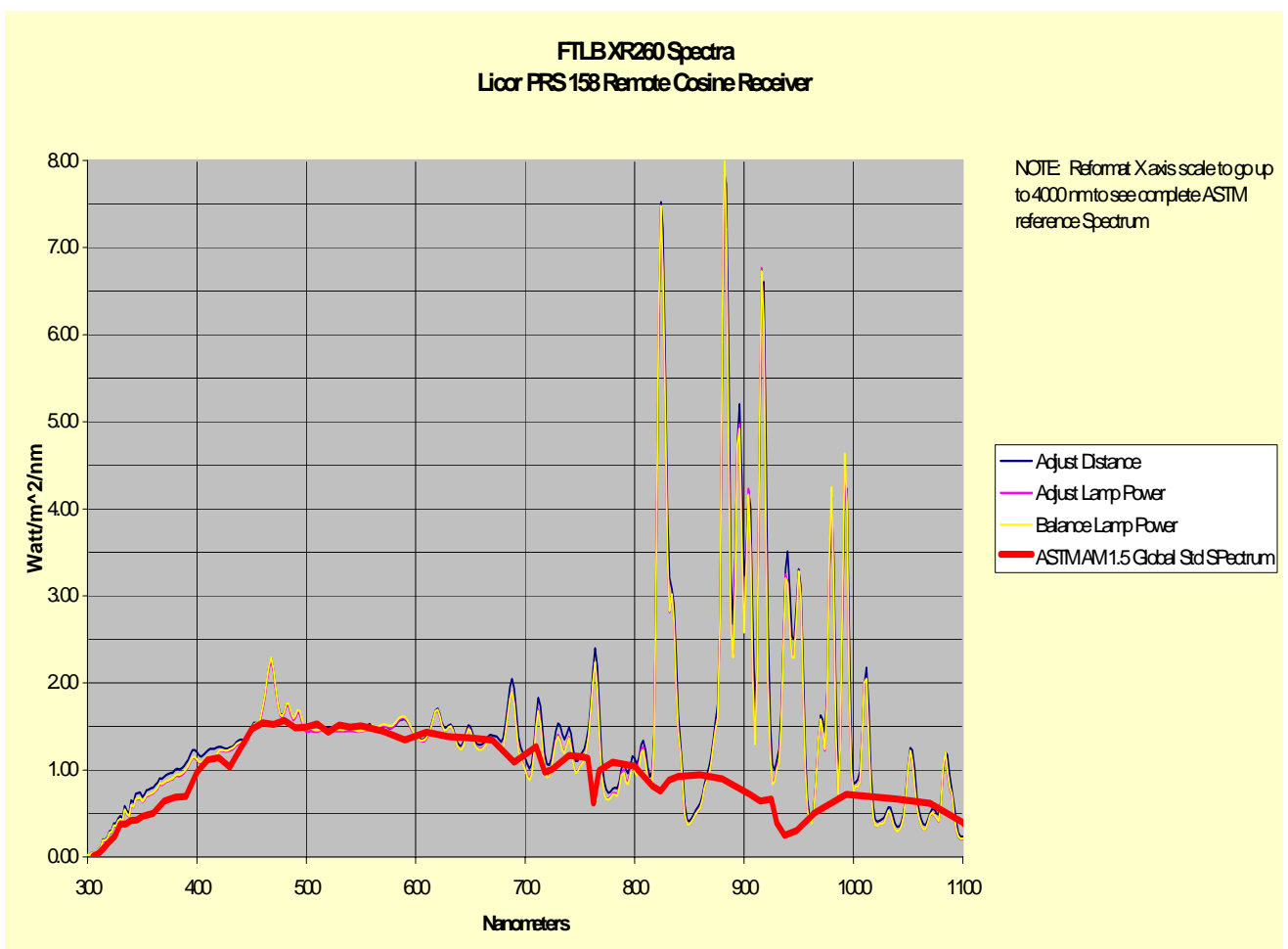

Figure 12 - Spectral distribution of the lamps in the Atlas test chamber compared with a typical solar spectrum

Each of the EC-IGU windows were outfitted with a 0.005”-diam. Type K thermocouple pasted to the top center surface with an $8 \mathrm{~mm}$-square patch of aluminum tape. Temperatures of the EC devices ranged from 68 to $78^{\circ} \mathrm{C}$ (with an average of $73^{\circ} \mathrm{C}$ ) depending on their position within the XR-260 chamber. Typical sinusoidal (bleach/color) variations in temperature with cycling are seen for the three devices.

Samples were cycled in the XR-260 chamber (EC film side facing the light source) initially using to achieve transmission ratios in excess of 5.0. Room temperature electrical characterization curves (current vs. time) for zero; 7,000, 14,000, 24,000, 34,000, 44,000, $54,000,64,000$ and 80,000 cycles of testing were recorded, as well as charge and discharge capacity curves for the devices cycled in the XR-260. Additionally, transmission as a function of wavelength data were recorded.

The following notes and general trends are evident from the data in these attachments as well as from visual observations of the devices:

\section{Bleached State Optical Characterization after 84,000 Cycles:}

The bleached state condition upon removal from the XR-260 environmental chamber of all three EC-IGU windows was carefully examined. The average photopic transmittance remained a virtual constant ( $\sim 59 \%)$ throughout the testing period. In general, all three devices 
appeared in good condition and exhibited bleached state transmittance values very similar to the previous test.

\section{Colored State Optical Characterization after 84,000 Cycles:}

Upon initial coloration, all devices show relatively good uniformity. The devices darkened to a very uniform blue/gray state of deep coloration. The windows appeared to exhibit no obvious degradation in their coloring characteristics during the test.

The transmittance of the devices in both the bleached and colored state conditions appear to have changed very little. The UV cut-on transmittance appears to have shifted slightly to higher wavelengths for all devices. Transmittance of the devices in the bleached state within the near IR region (900 to 1000nm) appears to exhibit a slight decrease but the Ocean Optics photo-diode array spectrometer used for this characterization is not reliable in this region.

The photopic transmittance values in the colored state after 80,000 cycles have basically remained unchanged $(\mathrm{E} 11=\sim 7 \%, \mathrm{E} 12=\sim 5 \%, \mathrm{E} 13=\sim 5 \%)$. At these low values, any minor variations in the colored state transmittance can translate into relatively significant changes in the photopic transmittance ratios. PTR values after 80,000 cycles of testing changed little also $(\mathrm{E} 11=\sim 8, \mathrm{E} 12=\sim 12, \mathrm{E} 13=\sim 13)$. In general, all the devices still functioned with a high bleached state transmittance, high photopic transmittance ratio, and a relatively good visual appearance devoid of any major cosmetic irregularities.

\section{Electrical Characterization after 84,000 Cycles:}

In general, the devices exhibited only minor differences in their color (3volt, 10min.) and bleach (-2volt, 10min.) curves. These electrical data basically support optical characterization data for the devices, which indicate little change in device performance since the last test sequence.

The charge/discharge capacity data taken during testing also indicate no basic changes in device performance between testing carried out after 64,000 cycles and that carried out at 80,000 cycles. Charge capacities (coloration) for all three devices range in value from 2.9 to $3.5 \times 10^{-3} \mathrm{~A}$.hr and remain relatively constant. Similarly, the discharge capacities (bleaching) of the devices range from 1.8 to $3.1 \times 10^{-3} \mathrm{~A}$.hr and also remain relatively constant. In general, the devices do not appear to have lost any kinetic performance when compared to their original ion-insertion characteristics. In overall perspective, all EC windows continued to exhibit deep uniform coloration and remarkable durability with no appearance of any new cosmetic aberrations across 80,000 cycles of testing.

\section{Summary:}

The SAGE EC-IGU windows (E11, E12 and E13) accumulated a total of $~ 80,000$ cycles of accelerated environmental testing under ASTM Standard E2141-02. This standard is designed to evaluate the combined degradative effects of heat, solar AM 1.5 light (1.1 UV sun equivalent) and extended electrical cycling. The windows were cycled alongside the large LS3 EC-IGU prototype window which resulted in reduced temperature conditions $\left(73^{\circ} \mathrm{C}\right.$ average) when compared to earlier tests. In general, all the devices still function with a high bleached state transmittance, high photopic transmittance ratio, little change in electrical characteristics and a relatively good visual appearance devoid of major cosmetic irregularities. Visual 
observations and photopic transmittance data in the bleached state indicate no obvious degradation $(\mathrm{E} 11=56 \%, \mathrm{E} 12=58 \%, \mathrm{E} 13=63 \%)$. As noted in our previous characterizations, all the devices exhibit a relatively uniform coloration in their intermediate color state and varying degrees of minor cosmetic defects with close examination. Upon further coloration to their fully darkened state, the devices continue to exhibit very dark and uniform blue/gray coloration. When compared to initial values, bleached state transmittances of the devices have remained relatively unchanged while average colored state transmittances have slightly increased from $5.2 \%$ to $5.7 \%$ on average.

Further, slightly less stringent in-house tests have added support to these observations. Devices are routinely 'solar-soaked' in in-house constructed solar soakers. No significant degradation is observed during these tests for standard devices. Furthermore, we have seen no deterioration in the performance after these solar-soaking tests as a result of the improvements we have made to the processing procedure during this project.

In general therefore, the SageGlass ${ }^{\circledR}$ devices appear to show excellent durability when tested under the relevant ASTM standard. This suggests that this particular inorganic lithium based technology is suitable for scale-up and commercialization.

\section{Discussion}

The project as a whole can be considered to have had two broad themes. First there are several process improvements, such as the process optimization and laser line isolation. Second there is the construction of some equipment aimed at increasing the production throughput or improving the overall quality. We will first discuss process improvements, with a view to determining whether they have produced an improvement in the overall process.

The highly complex behavior of the device, particularly regarding the dependence of the properties on the processing parameters, and their interdependence, sometimes makes it difficult to know whether an alteration to the process or processing equipment has actually had a beneficial effect. For example, a change to one processing parameter may lead to an improvement in one device characteristic, but may simultaneously cause another to degrade. One good example is the level of lithium inserted into the device. This can lead to an increase in the dynamic range, up to a point, but also an increase in the leakage current. There is clearly a trade-off which needs to be made in determining the level to insert. Further increases in the level will cause a further increase in leakage current, but now the device will show a reduced dynamic range, as the electronic leakage will tend to dominate the behavior, preventing the device from coloring fully. The question, therefore, is to determine the optimum level based on these competing requirements. One must therefore be careful to ensure that the results reported are not misleading as a result of considering only one parameter.

A further result which can be considered to be a process improvement is to achieve an increase in the consistency of the process, otherwise referred to as an improvement in the quality of the process. This allows further improvements to be implemented, as with a higher quality process, there is less noise in the experimental measurements taken to improve other parts of the process, thereby leading to clearer results.

In general, the process is tuned to give the best dynamic range, with the highest possible clear state transmission. Uniformity of individual layers can be monitored and adjusted separately, 
without necessarily affecting the overall dynamic range and clear state transmission. So, in general, the process can be considered to be relatively stable for these parameters, as any drift away from optimum will have been corrected by slight process adjustments. Changes to other parameters which are not directly controlled, such as leakage current, will therefore generally reflect overall process quality improvements.

An example illustrating this can be seen in Figure 13 where the leakage current of a particular size of device is plotted as a function of time. The time period spans the period where the Pilot Line was being operated, and also where the Production line was brought on-line. The leakage current is measured for every device produced, and is a function of a number of different things. These can be considered to be intrinsic - inherent to a perfectly produced stack of films, or extrinsic - caused by the disturbance around some sort of defect, such as an entrained dust particle.

Final Bleaching Current for one size of Electrochromic

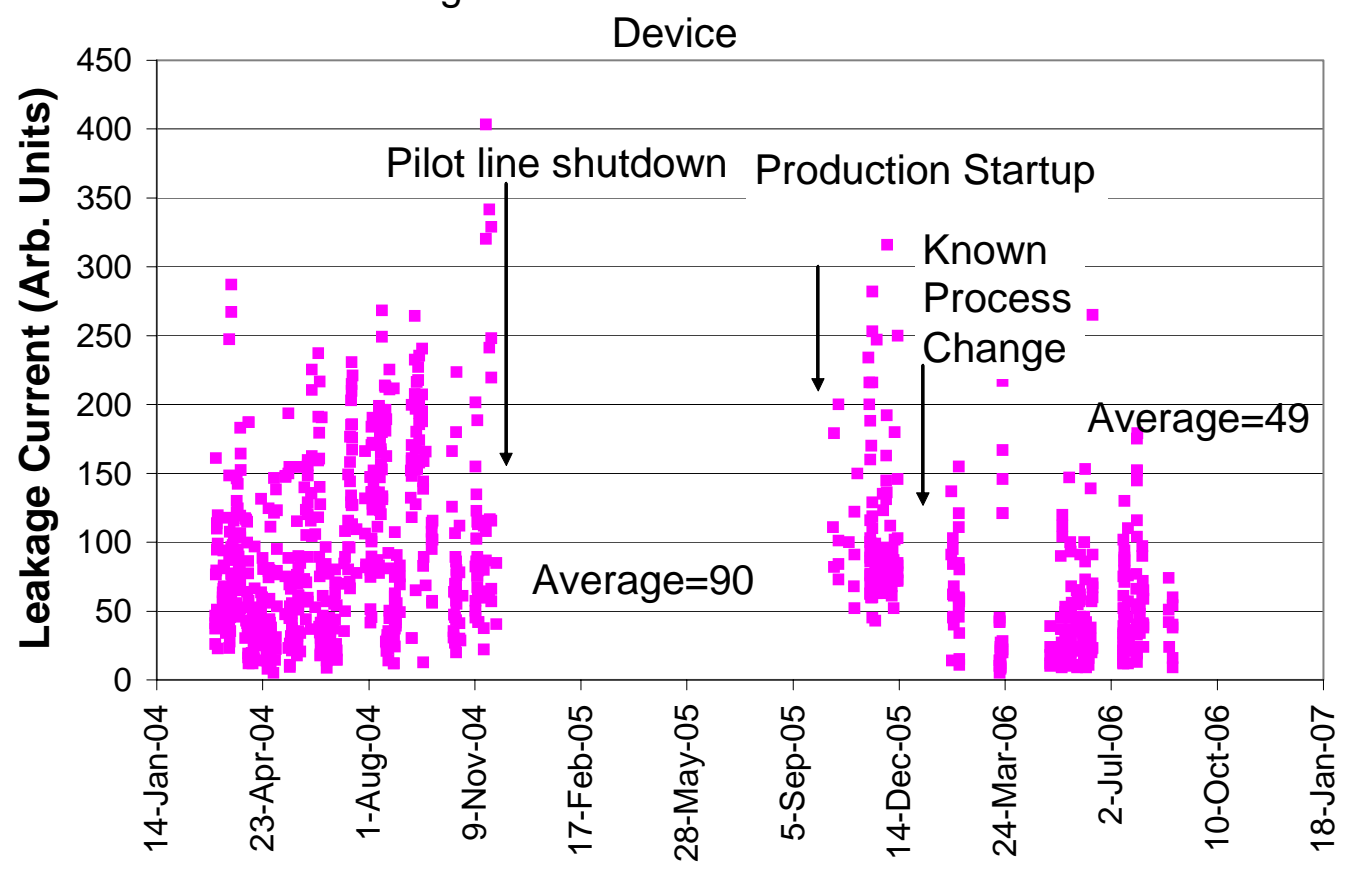

Figure 13 - Measured leakage current in clear state for EC devices of one size, produced during a period spanning the Pilot line and the production line.

First, the overall process can affect the level of leakage current, as the devices need to be produced with an accurately monitored level of charge. This can be thought of as intrinsic leakage, and this is addressed by optimizing the processing as discussed in Task 1.

Furthermore, there are several sources of extrinsic leakage. These are mostly related to point defects, usually associated with particles either embedded in the substrate, or entrained into the films as a result of contamination from the process. Both of these causes have been addressed by this project, the substrate quality issues have been dealt with by improving quality processes 
associated with glass handling and inspection, and cleanliness throughout the project having been improved as a result of the 6-sigma training.

A further contributor to leakage current was shown to be the film coverage of the sand-ablated line isolation. This was presumably due to the films not being able to follow the ragged topology across the line, thereby potentially resulting in thinned out regions. Replacing this process with a laser scribed line isolation results in a much cleaner line with better overall depth consistency and lower roughness. Presumably, this will lead to less leakage current as a result.

Overall, then we have made several changes which should result in lower overall leakage currents during this project as demonstrated by the data shown in Figure 13. In addition, it is anticipated that there should be better repeatability for many parameters, including the leakage current. This can be seen for this measurement, as the overall level of leakage has reduced from the period prior to the project start compared with the period after the project. At the same time the overall scatter of the measurements has also reduced, showing an improvement in the overall consistency of this most complicated production process.

One important additional aspect which needs to be considered during this work is that there should be no deterioration in the durability of the devices as a result of any changes made to the process. We have seen that the SageGlass ${ }^{\circledR}$ product displays excellent durability overall. However, in the past we have found that higher leakage currents generally lead to instability in long term durability cycling, possibly leading to non-uniform coloration. Demonstrating a reduction in the leakage current will therefore have a beneficial effect on the long term durability. Indeed, no tests we have carried out have shown any compromise to the durability of the devices, and so we can consider this aspect of the project to be successful.

The final parts of the project were to design and fabricate some pieces of process equipment designed to make processing more repeatable or to improve process throughput. Both pieces of equipment, a laser scriber for producing the line isolation in the transparent conductive coating, and an automatic rework station to allow short circuit defects to be located and eliminated by using a grid of electrical contacts to sense the potential distribution around the short, were constructed and demonstrated successfully. Once again, this must be considered a success for the project, and the laser scriber has now been incorporated into the production process. It was determined that the automatic rework station was successful, but it was found to be somewhat difficult to use, as it involved moving the samples backwards and forwards between the test equipment and the rework station. Additionally, there became a need to rework shorts within a completed IGU, which meant that the contact method on which the equipment was based was impossible to use. 


\section{Appendix A. Final Task Schedule}

Final Task Schedule

\begin{tabular}{|c|c|c|c|c|c|c|}
\hline \multirow{2}{*}{$\begin{array}{c}\text { Task } \\
\text { Number }\end{array}$} & \multirow{2}{*}{ Task Description } & \multicolumn{4}{|c|}{ Task Completion Date } & \multirow{2}{*}{ Progress Notes } \\
\cline { 3 - 6 } & $\begin{array}{c}\text { Original } \\
\text { Planned }\end{array}$ & $\begin{array}{c}\text { Revised } \\
\text { Planned }\end{array}$ & Actual & $\begin{array}{c}\text { Percent } \\
\text { Complete }\end{array}$ & \\
\hline 1 & Process Improvement & $04 / 30 / 04$ & $04 / 30 / 05$ & $04 / 30 / 05$ & $100 \%$ & Completed. \\
\hline 2 & Glazing Rework & $02 / 28 / 04$ & $02 / 28 / 05$ & $02 / 28 / 05$ & $100 \%$ & Completed. \\
\hline 3 & Laser Patterning & $02 / 28 / 04$ & $04 / 30 / 05$ & $04 / 30 / 05$ & $100 \%$ & Completed. \\
\hline 4 & $\begin{array}{c}\text { Qualification/Durability } \\
\text { Testing }\end{array}$ & $7 / 28 / 04$ & $5 / 1 / 06$ & $5 / 1 / 06$ & $100 \%$ & Completed. \\
\hline 5 & Project Management & $10 / 31 / 04$ & $5 / 1 / 06$ & $9 / 11 / 06$ & $100 \%$ & Completed. \\
\hline
\end{tabular}

There was a delay of approximately 12 months due to a financial hold up after the project was approved. This lead to a later completion date than originally anticipated. In addition, a one year no cost time extension was applied for and granted to allow for testing in our new production facility and for additional long term durability testing. 


\section{Appendix B. Final Spending Schedule}

Final Spending Schedule

Project Period: $\quad$ 05/01/03 to 05/01/06

\begin{tabular}{|c|c|c|}
\hline Task & Approved Budget & Final Project Expenditures \\
\hline Task 1 Process Improvement & 146,305 & 146,305 \\
\hline Task 2 Glazing Rework & 57,961 & 57,961 \\
\hline Task 3 Laser Patterning & 43,935 & 43,935 \\
\hline $\begin{array}{cl}\text { Task } 4 \text { Qualification/Durability } \\
\text { Testing }\end{array}$ & 16,535 & 16,535 \\
\hline Task 5 Project Management & 8,953 & 8,953 \\
\hline Total & 273,689 & 273,689 \\
\hline DOE Share & 200,000 & 200,000 \\
\hline Cost Share & 73,689 & 73,689 \\
\hline
\end{tabular}




\section{Appendix C. Final Cost Share Contributions}

Final Cost Share Contributions

\begin{tabular}{|r|c|c|c|c|}
\hline \multirow{2}{*}{ Funding Source } & \multicolumn{2}{|l|}{ Approved Cost Share } & \multicolumn{2}{l|}{ Final Contributions } \\
\cline { 2 - 5 } & Cash & In-Kind & Cash & In-Kind \\
\hline SAGE & & 73,689 & & 73,689 \\
\hline & & & & \\
\hline & & & & \\
\hline & & & & 73,689 \\
\hline Total & & 73,689 & & 73,689 \\
\hline
\end{tabular}




\section{Appendix D. Energy Savings Metrics}

This project focused on developing advanced fabrication capabilities of energy-saving electrochromic smart windows. Analysis of energy savings in a single residence is presented below; however, national energy savings depends on the market penetration of these windows. Studies at Pacific Northwest National Laboratories show that market penetration is dependent on the price of EC windows when compared to currently available low-e advanced glazings. ${ }^{11}$ This work to improve manufacturability and increase yields will accelerate cost reductions to achieve a selling price of \$25/sq.ft. by 2011 and \$15/sq.ft. by 2017 .

Table 6 - Window Specifications

\begin{tabular}{|c|c|c|}
\hline Window & U-factor & SHGC \\
\hline SAGE EC dynamic window & 0.28 & 0.48 clear, $0.16^{*}$ tinted \\
\hline High gain low-e window & 0.37 & 0.53 \\
\hline
\end{tabular}

*The LBNL analysis was carried out assuming 0.16 SHGC for dynamic windows during cooling periods. SAGE glazings achieve SHGC of 0.09 when tinted. Consequently this analysis is very conservative and actual energy savings with SAGE glazings will be greater than the results presented below.

In this analysis, we consider the energy saving benefits of electrochromic windows in residential housing. Annual heating and cooling energy use in homes for a variety of climate conditions was calculated by Lawrence Berkeley National Laboratories (LBNL) using DOE-2 simulations. ${ }^{12}$ The building used in the model was a 2000 square foot single family residence with 300 square feet of windows distributed equally on all four orientations.

The LBNL data can be used to compare annual heating and cooling energy for a home with SAGE EC windows to the same home with double glazed, high gain, low-e windows. The window properties are listed in Table 6.

The LBNL:work showed that the average HVAC energy savings for a home in Riverside, CA was $\sim 30 \%$. The Energy Saving Metrics are presented in Table 7.

The splits of end-use energy among the various fuel types is from Table 1.2.3, 2005 Buildings Energy Data Book. The total number of single family homes in 2010 is estimated from Table 2.1.1 in the Data Book.

\footnotetext{
${ }^{11}$ Elliot, D.B. et. al., "Methodological Framework for Analysis of Buildings-Related Programs: The GPRA Metrics Effort, PNNL-14697, Pacific Northwest national Laboratory, Richland, Washington, 2004.

12 Dariush Arasteh, Howdy Goudey, Joe Huang, Christian Kohler, and Robin Mitchell Windows and Daylighting Group Lawrence Berkeley National Laboratory Berkeley CA 94720 LBNL Report LBNL-59190, Draft, Dec. 2005.
} 
Table 7 - Energy Savings Metrics

\begin{tabular}{|c|c|c|c|c|c|}
\hline \multirow{3}{*}{$\begin{array}{c}\text { Type of Energy } \\
\text { Used }\end{array}$} & A & B & $C=A-B$ & D & $E=C x D$ \\
\hline & $\begin{array}{l}\text { High Gain } \\
\text { low-e }\end{array}$ & SAGE-EC & $\begin{array}{l}\text { Energy } \\
\text { Savings }\end{array}$ & $\begin{array}{c}\text { Estimated } \\
\text { Number of } \\
\text { Homes in U.S. } \\
\text { by } 2010\end{array}$ & $\begin{array}{l}\text { Energy } \\
\text { Savings by } \\
2010\end{array}$ \\
\hline & $\begin{array}{c}\text { (MBtu I yr I } \\
\text { unit) }\end{array}$ & $\begin{array}{c}\text { (MBtu / yr I } \\
\text { unit) }\end{array}$ & (MBtu / yr / unit) & (units) & (Btu / yr) \\
\hline Fuel Oil & 2.8 & 2.0 & 0.8 & & \\
\hline Natural Gas & 12.5 & 8.7 & 3.8 & & \\
\hline \multicolumn{6}{|l|}{ Coal } \\
\hline $\begin{array}{c}\text { Electricity (@ } \\
\text { 10,500 Btu / kWh) }\end{array}$ & 13.5 & 9.4 & 4.1 & & \\
\hline LPG, Renewables & 2.7 & 1.9 & 0.8 & & \\
\hline \multicolumn{6}{|l|}{$\begin{array}{l}\text { Other Energy } 2 \\
\text { (Explain) }\end{array}$} \\
\hline \multicolumn{6}{|l|}{$\begin{array}{l}\text { Other Energy ...n } \\
\quad \text { (Explain) }\end{array}$} \\
\hline Total Per Unit & 31.5 & 22.0 & 9.5 & $100 \times 10^{6}$ & $0.95 \times 10^{15}$ \\
\hline
\end{tabular}

In Table 7, the annual energy savings of a single residence with SAGE EC windows is 9.5MBtu. The maximum national energy saving is calculated assuming that all homes in 2010 (100 million) are built and/or retrofitted with EC glazings. The resulting national energy savings is 0.95 quad. Although complete conversion in this time frame is unrealistic, the data are useful in evaluating the long term benefits of dynamic windows.

The market penetration of EC smart windows is a strong function of price. This project to improve EC processing will enable SAGE to sell dynamic IG units at \$25/sq. ft. by 2011 and the price is expected to drop to $\$ 15 / \mathrm{sq} / \mathrm{ft}$. by 2017 . Based on PNNL market diffusion models, EC penetration of the advanced glazing (low-e) residential market is estimated to be $8 \%$ in 
2011, and 14\% in 2017. ${ }^{13}$ Current advanced (low-e) market penetration is roughly $40 \%$ of the new and retrofit residential market, which is expected to grow in the next few years.

New window sales are evenly distributed among new construction and existing buildings. Each year, approximately $1.6 \mathrm{M}$ residential construction permits are issued in the US, and new windows will be purchased for these units. We assume there will be an equal number of existing homes retrofitted with new windows. ${ }^{14}$

2011 Calculation:

Since 2006 (5 years) we conservatively estimate that 16M new and existing homes will constructed and retrofitted with new windows. We estimate that the average penetration of this market will be 4\% (8\% penetration in year 2011). This corresponds to 640,000 homes in 2011 with annual energy savings of:

$\left(9.5 \times 10^{6}\right.$ Btu/year $)(640,000$ homes $)=\mathbf{6 \times 1 0} \mathbf{1 2}^{\mathbf{1 2}}$ Btu.

\section{Calculation}

Between 2011 and 2017, we estimate that the total number of new and renovated homes (at $3.2 \mathrm{M} / \mathrm{yr})$ is $19.2 \mathrm{M}$. The average penetration of this market is estimated at $11 \%(14 \%$

penetration in year 2017). This corresponds to 2.1M additional homes in 2017 with annual energy saving of:

\section{$6 \times 10^{12}$ Btu existing $+2 \times 10^{13}$ Btu additional $=2.6 \times 10^{13}$ Btu Total Residential Savings in} 2017.

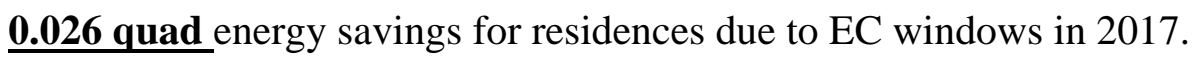

\footnotetext{
${ }^{13}$ Projected Benefits of Federal Energy Efficiency and Renewable Energy Programs, National Renewable Energy Laboratory, NREL/TP-620-37931, March 2005.

14 Ibid.
} 